\title{
Laboratory Evaluation of the Sequoia Scientific LISST-ABS Acoustic Backscatter Sediment Sensor
}

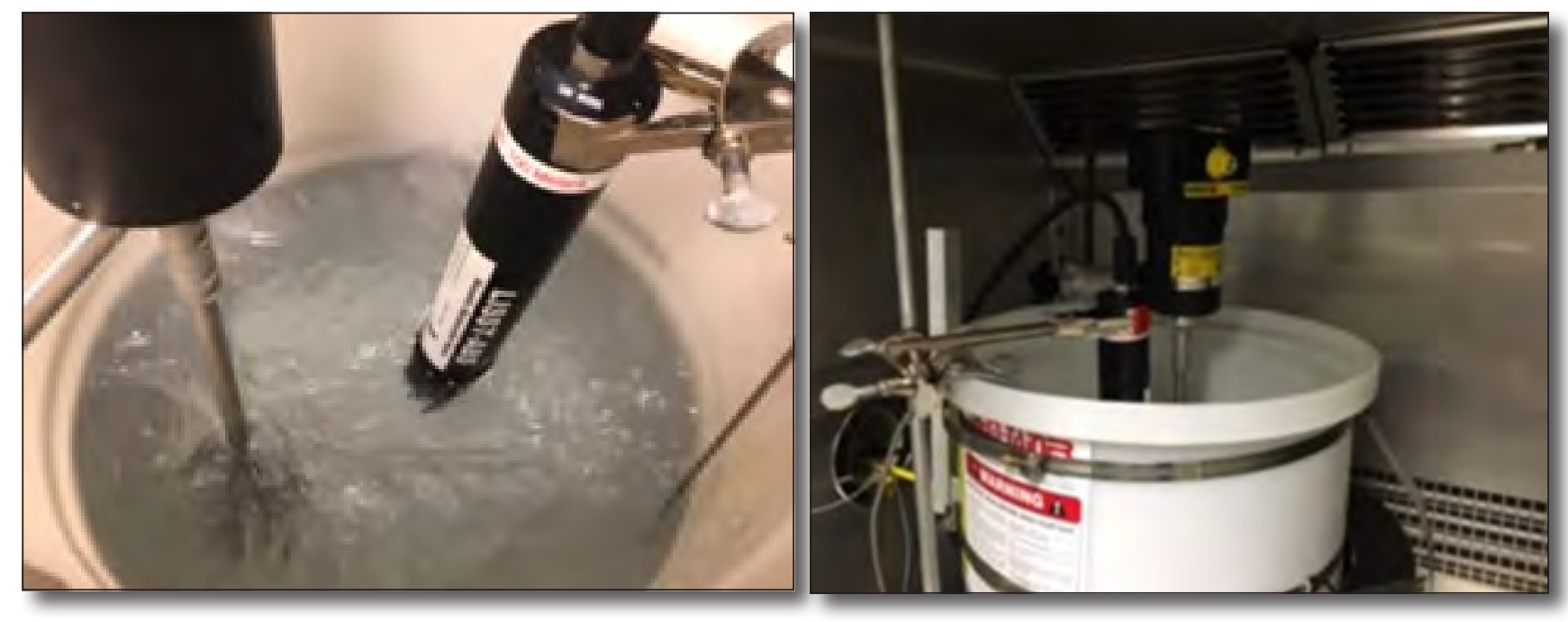

Open-File Report 2017-1154 
Cover. Photographs showing, left, the LISST-ABS sensor, electric mixer, and thermistor probe mounted in the mixing tank (see figure 2); and, right, test mixing tank setup containing the electric mixer and the LISST-ABS in the environmental chamber (see figure 3). 


\section{Laboratory Evaluation of the Sequoia Scientific LISST-ABS Acoustic Backscatter Sediment Sensor}

By Teri T. Snazelle

Open-File Report 2017-1154 


\title{
U.S. Department of the Interior \\ RYAN K. ZINKE, Secretary
}

\section{U.S. Geological Survey William H. Werkheiser, Deputy Director exercising the authority of the Director}

\author{
U.S. Geological Survey, Reston, Virginia: 2017
}

For more information on the USGS - the Federal source for science about the Earth, its natural and living resources, natural hazards, and the environment—visit http://www.usgs.gov or call 1-888-ASK-USGS.

For an overview of USGS information products, including maps, imagery, and publications, visit http://store.usgs.gov.

Any use of trade, firm, or product names is for descriptive purposes only and does not imply endorsement by the U.S. Government.

Although this information product, for the most part, is in the public domain, it also may contain copyrighted materials as noted in the text. Permission to reproduce copyrighted items must be secured from the copyright owner.

Suggested citation:

Snazelle, T.T., 2017, Laboratory evaluation of the Sequoia Scientific LISST-ABS acoustic backscatter sediment sensor: U.S. Geological Survey Open-File Report 2017-1154, 21 p., https://doi.org/10.3133/ofr20171154.

ISSN 2331-1258 (online) 


\section{Acknowledgments}

The author thanks Dr. Mark Landers, Chief, Federal Interagency Sedimentation Project; and the members of the Federal Interagency Sedimentation Project for supplying the sensors. A special thank you is extended to the members of the U.S. Geological Survey LISST-ABS work group for their insight and guidance with this project. 


\section{Contents}

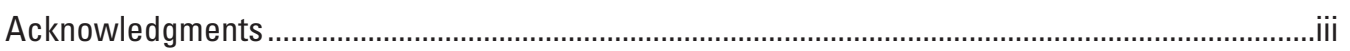

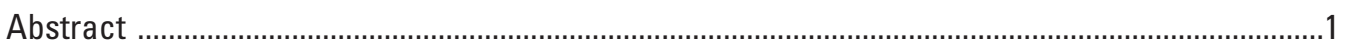

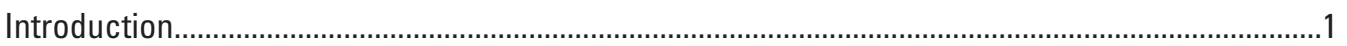

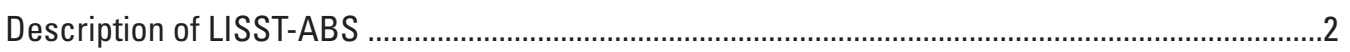

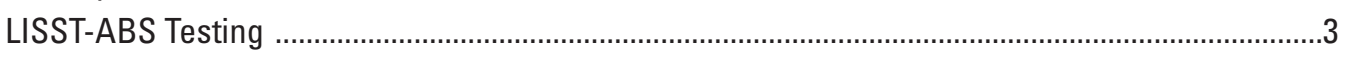

Test Procedures: Room-Temperature Testing of Sensor 6010 ................................................

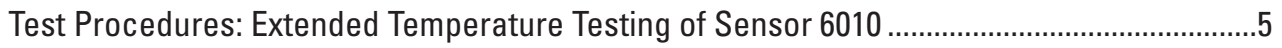

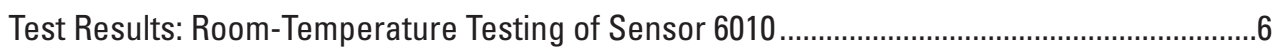

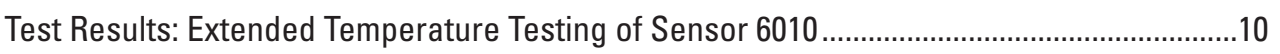

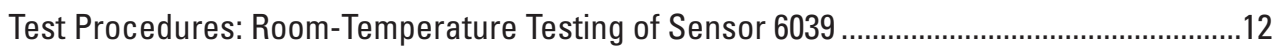

Test Procedures: Extended Temperature Testing of Sensor 6039 ........................................12

Test Results: Room-Temperature Testing of Sensor 6039 ......................................................13

Test Results: Extended Temperature Testing of Sensor 6039 ....................................................16

Test Procedures: Room-Temperature Testing of Sensor 6058 ..............................................16

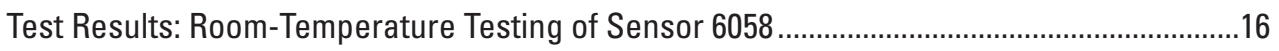

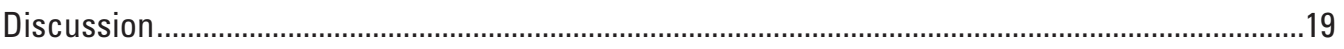

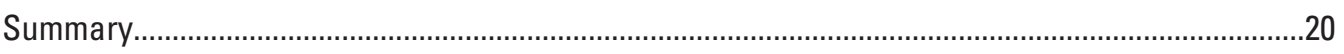

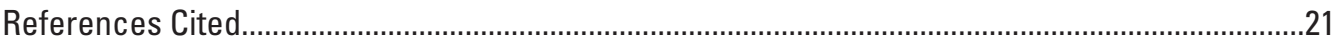

\section{Figures}

1. Image showing Sequoia Scientific's LISST-ABS and the dimensions of the sensor ........2

2. Photograph showing the LISST-ABS, electric mixer, and thermistor probe mounted in the mixing tank with 25 liters of water and characterized sediment.............................

3. Photographs showing the test mixing tank setup containing the electric mixer and the LISST-ABS in the environmental chamber...

4. Plot showing the theoretical linear and normalized measured response of the Sequoia Scientific LISST-ABS to increasing ISO 12103-1, A1 Ultrafine Test Dust suspended-sediment concentration after calibration with 12103-1, A1 Ultrafine Test Dust.

5. Plot showing the theoretical linear and normalized measured response of the Sequoia Scientific LISST-ABS to increasing Arizona Test Dust suspended-sediment concentrations, after calibration with Arizona Test Dust.

6. Plot showing the theoretical linear and normalized measured response of the Sequoia Scientific LISST-ABS and the resulting suspended-sediment concentrations to additions of MIL-STD-810E Silica Dust after calibration with ISO 12103-1, A1 Ultrafine Test Dust

7. Plot showing the theoretical linear and normalized measured response of sensor 6010, and the resulting suspended-sediment concentrations to additions of MIL-STD-810E Silica Dust after calibration with Arizona Test Dust...

8. Plot showing the collective results from three temperature tests of sensor 6010 showing the effect of varying temperatures on measured suspendedsediment concentration of a 100-milligram-per-liter Arizona Test Dust solution

9. Graph showing the composition of the HIF test mix used in calibration testing of Sequoia Scientific LISST-ABS 
10. Plot showing the theoretical linear and normalized response of sensor 6039, and the resulting suspended-sediment concentration to additions of MIL-STD-810E

Silica Dust, after calibration with ISO 12103-1, A1 Ultrafine Test Dust......

11. Plot showing the theoretical linear and normalized response of sensor 6039, and the resulting suspended-sediment concentration to additions of ISO 12103-1, A1 Ultrafine Test Dust, after calibration with MIL-STD-810E Silica Dust.

12. Plots showing the theoretical linear and normalized responses of sensor 6039 and the resulting suspended-sediment concentrations to additions of ISO 12103-1, A1 Ultrafine Test Dust and Arizona Test Dust, after calibration with HIF test mix...........15

13. Plot showing the effects of varying temperatures on measured suspendedsediment concentration of a 100-milligram-per-liter Arizona Test Dust solution during the temperature test of Sequoia Scientific LISST-ABS .

14. Plot showing the theoretical linear and normalized response of sensor 6058, and the resulting suspended-sediment concentration to additions of MIL-STD-810E Silica Dust, after calibration with ISO 12103-1, A1 Ultrafine Test Dust.

15. Plot showing the theoretical linear and measured response of sensor 6058 , and the resulting suspended-sediment concentration in milligrams per Liter, to additions of ISO 12103-1, A1 Ultrafine Test Dust, after calibration with MIL-STD-810E Silica Dust.

16. Plot showing the theoretical linear and normalized response of sensors 6010 , 6039 , and 6058 and the resulting suspended-sediment concentration to additions of MIL-STD-810E Silica Dust, when calibrated with ISO 12103-1, A1 Ultrafine Test Dust..

17. Plot showing the theoretical linear and normalized responses of sensors 6039 and 6058 , and the resulting suspended-sediment concentrations, to additions of ISO 12103-1, A1 Ultrafine Test Dust, when calibrated with MIL-STD-810E Silica Dust.

\section{Tables}

1. Features and technical specifications of Sequoia Scientific's LISST-ABS

2. Sediment samples' aggregate classes, particle sizes, and particle-size distributions ....4

3. Sequoia Scientific LISST-ABS SSC measurements at room temperature in various concentrations of ISO 12103-1, A1 Ultrafine Test Dust withfactory calibration and after calibration with ISO 12103-1, A1 Ultrafine Test Dust.

4. Sequoia Scientific LISST- ABS SSC measurements at room temperature in various concentrations of Arizona Test Dust after calibration with ISO 12103-1 A1 Ultrafine Test Dust and after calibration with Arizona Test Dust

5. Sequoia Scientific LISST- ABS SSC measurements in increasing proportions of MIL-STD-810E Silica Dust to ISO 12103-1, A1 Ultrafine Test Dust after calibration with ISO 12103-1, A1 Ultrafine Test Dust at room temperature.

6. Sequoia Scientific LISST- ABS SSC measurements in increasing proportions of MILSTD-810E Silica Dust to Arizona Test Dust after calibration with Arizona Test Dust........9

7. Sequoia Scientific LISST-ABS SSC measurements and percent difference from sample concentration in $100-\mathrm{mg} / \mathrm{L}$ concentration of Arizona Test Dust at various temperatures during an initial test.

8. Sequoia Scientific LISST-ABS SSC measurements and percent difference from sample concentration in $100-\mathrm{mg} / \mathrm{L}$ concentration of Arizona Test Dust at various temperatures during a repeated lower temperature test..

9. Sequoia Scientific LISST-ABS SSC measurements showing the effect of MIL-STD-

810E Silica Dust on the ISO 12103-1, A1 Ultrafine Test Dust calibration 
10. Sequoia Scientific LISST-ABS SSC measurements showing the effect of ISO 12103-1, A1 Ultrafine Test Dust on the MIL-STD-810E Silica Dust calibration

11. Sequoia Scientific LISST-ABS SSC measurements showing the effect of ISO 12103-1, A1 Ultrafine Test Dust and Arizona Test Dust on the HIF test mix calibration.

12. Sequoia Scientific LISST-ABS SSC measurements showing the effect of MILSTD-810E Silica Dust on the ISO 12103-1, A1 Ultrafine Test Dust calibration

13. Sequoia Scientific LISST-ABS SSC measurements showing the effect of ISO 12103-1, A1 Ultrafine Test Dust on the MIL-STD-810E Silica Dust calibration

\section{Conversion Factors}

International System of Units to U.S. customary units

\begin{tabular}{lcl}
\hline \multicolumn{1}{c}{ Multiply } & By & \multicolumn{1}{c}{ To obtain } \\
\hline \multicolumn{3}{c}{ Length } \\
micrometer or micron $(\mu \mathrm{m})$ & 0.00003937 & inch (in.) \\
centimeter $(\mathrm{cm})$ & 0.3937 & inch (in.) \\
\hline \multicolumn{3}{c}{ Volume } \\
\hline liter (L) & 33.81402 & ounce, fluid (fl. oz) \\
liter (L) & 2.113 & pint (pt) \\
liter (L) & 1.057 & quart (qt) \\
liter (L) & 0.2642 & gallon (gal) \\
liter (L) & 61.02 & cubic inch (in $\left.{ }^{3}\right)$ \\
\hline & Mass & \\
\hline gram (g) & 0.03527 & ounce, avoirdupois (oz) \\
\hline
\end{tabular}

U.S. customary units to International System of Units

\begin{tabular}{lcl}
\hline \multicolumn{1}{c}{ Multiply } & \multicolumn{1}{c}{ To obtain } \\
\hline inch (in.) & Length & \\
inch (in.) & $25,400.0$ & micrometer or micron $(\mu \mathrm{m})$ \\
\hline \multicolumn{3}{c}{ Volume } \\
\hline gallon (gal) & 3.785 & centimeter $(\mathrm{cm})$ \\
\hline \multicolumn{3}{c}{ Flow rate $(\mathrm{L})$} \\
\hline foot per second (ft/s) & 0.3048 & meters per second $(\mathrm{m} / \mathrm{s})$ \\
\hline & Mass & \\
\hline pound, avoirdupois $(\mathrm{lb})$ & $453,592.37$ & milligram $(\mathrm{mg})$ \\
\hline
\end{tabular}

Temperature in degrees Celsius $\left({ }^{\circ} \mathrm{C}\right)$ may be converted to degrees Fahrenheit $\left({ }^{\circ} \mathrm{F}\right)$ as follows:

$$
{ }^{\circ} \mathrm{F}=\left(1.8 \times{ }^{\circ} \mathrm{C}\right)+32
$$

Temperature in degrees Fahrenheit $\left({ }^{\circ} \mathrm{F}\right)$ may be converted to degrees Celsius $\left({ }^{\circ} \mathrm{C}\right)$ as follows:

$$
{ }^{\circ} \mathrm{C}=\left({ }^{\circ} \mathrm{F}-32\right) / 1.8
$$

Concentrations of chemical constituents in water are given in milligrams per liter (mg/L). 


\section{Abbreviations}

$\begin{array}{ll}\text { ABS } & \text { acoustic backscatter sensor } \\ \text { ACB } & \text { attenuation corrected backscatter } \\ \text { ADCP } & \text { acoustic Doppler current profiler } \\ \text { FNU } & \text { formazin nephelometric unit } \\ \text { HIF } & \text { Hydrologic Instrumentation Facility (USGS) } \\ \text { MHz } & \text { megahertz } \\ \text { NTU } & \text { nephelometric turbidity unit } \\ \text { SDI } & \text { serial data interface } \\ \text { SSC } & \text { suspended-sediment concentration } \\ \text { USB } & \text { universal serial bus } \\ \text { USGS } & \text { U.S. Geological Survey }\end{array}$





\title{
Laboratory Evaluation of the Sequoia Scientific LISST-ABS Acoustic Backscatter Sediment Sensor
}

\author{
By Teri T. Snazelle
}

\begin{abstract}
Sequoia Scientific's LISST-ABS is an acoustic backscatter sensor designed to measure suspended-sediment concentration at a point source. Three LISST-ABS were evaluated at the U.S. Geological Survey (USGS) Hydrologic Instrumentation Facility (HIF). Serial numbers 6010, 6039, and 6058 were assessed for accuracy in solutions with varying particle-size distributions and for the effect of temperature on sensor accuracy. Certified sediment samples composed of different ranges of particle size were purchased from Powder Technology Inc. These sediment samples were 30-80-micron $(\mu \mathrm{m})$ Arizona Test Dust; less than 22- $\mu \mathrm{m}$ ISO 12103-1, A1 Ultrafine Test Dust; and 149- $\mu \mathrm{m}$ MIL-STD 810E Silica Dust. The sensor was able to accurately measure suspended-sediment concentration when calibrated with sediment of the same particle-size distribution as the measured. Overall testing demonstrated that sensors calibrated with finer sized sediments overdetect sediment concentrations with coarser sized sediments, and sensors calibrated with coarser sized sediments do not detect increases in sediment concentrations from small and fine sediments. These test results are not unexpected for an acoustic-backscatter device and stress the need for using accurate site-specific particle-size distributions during sensor calibration. When calibrated for ultrafine dust with a less than $22-\mu \mathrm{m}$ particle size (silt) and with the Arizona Test Dust with a 30-80- $\mu \mathrm{m}$ range, the data from sensor 6039 were biased high when fractions of the coarser $(149-\mu \mathrm{m})$ Silica Dust were added. Data from sensor 6058 showed similar results with an elevated response to coarser material when calibrated with a finer particle-size distribution and a lack of detection when subjected to finer particle-size sediment. Sensor 6010 was also tested for the effect of dissimilar particle size during the calibration and showed little effect. Subsequent testing revealed problems with this sensor, including an inadequate temperature compensation, making this data questionable. The sensor was replaced by Sequoia Scientific with serial number 6039. Results from the extended temperature testing showed proper temperature compensation for sensor 6039, and results from the dissimilar calibration/testing particle-size distribution closely corroborated the results from sensor 6058.
\end{abstract}

\section{Introduction}

Sequoia Scientific's LISST-ABS is a submersible acoustic backscatter sensor designed to measure suspended-sediment concentration (SSC) at a point source. The advantages of an acoustic backscatter sensor over traditional, optical turbidity sensors are less sensitivity to grain size, less susceptibility to fouling, and a larger working range in concentration (Landers and others, 2016; Sequoia Scientific, 2016a). The simplified reporting units of the LISST-ABS is another advantage of the sensor. Measurement reporting units that are specific to the instrument type, such as those needed with optical turbidity sensors, can result in poor measurement comparability between sensor types in environmental samples (Anderson, 2005). The acoustic sensor has an advantage over traditional optical sensors in the simplified reporting units in milligrams per liter, assuming that a reliable calibration coefficient is used for each instrument and installation. Evaluation testing of the Sequoia Scientific LISST-ABS was performed at the U.S. Geological Survey (USGS) Hydrologic Instrumentation Facility (HIF) to assess the accuracy of the sensor in several suspended-sediment solutions with varying particle-size distributions.

The HIF evaluates the performance of instruments and equipment that are used to measure hydrologic data. Instrument and equipment evaluations are done primarily to determine if particular devices would be suitable for use by USGS personnel for hydrologic data collection. Evaluation reports document the results obtained with the instrument model and firmware used at the time of testing, and may or may not represent results obtained from software updates and instrument model improvements. Reports describing the instrument evaluation results are not indicative of an endorsement by the USGS of the tested instrument. This report documents the laboratory evaluation of the Sequoia Scientific LISST-ABS (ABS). Test results for three sensors are presented. All sensors were tested with the LISST software product version 1.4. After a brief description of the sensor, the laboratory test procedures and results are described. 


\section{Description of LISST-ABS}

Sequoia Scientific's LISST-ABS is an acoustic sensor that operates at a frequency of 8 megahertz (MHz) (Sequoia Scientific, 2016b) (fig. 1 and table 1). Unlike an acoustic Doppler current profiler (ADCP), the ABS is designed to measure SSC at a fixed point instead of multiple points along the acoustic beam. To operate, the sensor's ceramic transducer initiates a short pulse of high-frequency sound. Particles in the water scatter and attenuate this sound pulse in all directions. The portion of the sound energy that is reflected back toward the ceramic transducer is the measured backscatter. Sequoia Scientific chose the 5.5-centimeter $(\mathrm{cm})$ in-water path to minimize the effects of sound attenuation and water temperature on the measurement (Sequoia Scientific, 2016b).

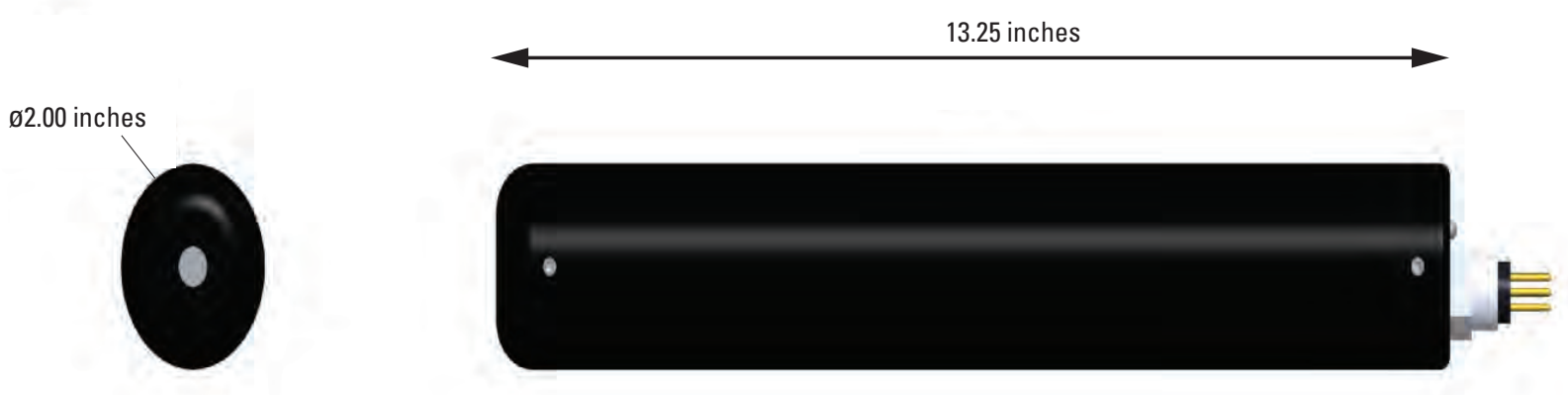

Figure 1. Sequoia Scientific's LISST-ABS and the dimensions of the sensor. (Image courtesy of Sequoia Scientific, 2016, used with permission.)

Table 1. Features and technical specifications of Sequoia Scientific's LISST-ABS (Sequoia Scientific, 2016a).

[cm, centimeter; MHz, megahertz; mm, millimeter; kg, kilogram; lb, pound; in., inch; mg/L, milligram per liter; $\mathrm{g} / \mathrm{L}$, gram per liter; \%, percent; m, meter; VDC, volts direct current; mA, milliamp; V, volt; dB, decibel]

\begin{tabular}{ll}
\hline \multicolumn{1}{c}{ Feature } & \multicolumn{1}{c}{ Specification } \\
\hline Acoustic operation & Point sensor $(5.5 \mathrm{~cm}$ in front of sensor) \\
Operating frequency & $8 \mathrm{MHz}$ \\
Transducer & $10-\mathrm{mm}$ diameter, ceramic \\
Weight & $0.5 \mathrm{~kg}$ or $1 \mathrm{lb}$ \\
Length & $33.65 \mathrm{~cm}$ or $13.25 \mathrm{in}$. \\
Range & $1 \mathrm{mg} / \mathrm{L}$ to $70 \mathrm{~g} / \mathrm{L}$ (in $7-$ micron dust) \\
& $1 \mathrm{mg} / \mathrm{L}$ to $50 \mathrm{~g} / \mathrm{L}$ (in 200 -micron sand) \\
Resolution & $0.5 \%$ of reading \\
Max depth & $100 \mathrm{~m}$ \\
Power requirements & $9-18 \mathrm{VDC}, 100 \mathrm{~mA}$ \\
Output & $0-5 \mathrm{~V}$ for $0-100 \mathrm{~dB}$ analog, SDI-12, or RS-232 \\
Material & Acryonitrile butadiene styrene plastic \\
\hline
\end{tabular}


The ABS does not have internal data storage and power, and must be powered externally. To communicate with the ABS, the user must connect the accompanying cable with a universal serial bus (USB) connector to a computer with the accompanying Sequoia Scientific LISST-ABS software installed on it. Sensor outputs include analog, digital (RS-232), and serial data interface at 1,200 baud (SDI-12) (Sequoia Scientific, 2016b). The ABS internally measures the attenuation-corrected backscatter (ACB) of a solution, which is converted and ouput as uncalibrated suspended-sediment concentration $\left(\mathrm{SSC}_{\mathrm{u}}\right)$. $\mathrm{SSC}_{\mathrm{u}}$ is converted to SSC in milligrams per liter by:

$$
S S C=S S C_{u} * \text { Cal Factor }
$$

where Cal Factor is computed by the software during the calibration of the sensor with the selected calibration sediment.

\section{LISST-ABS Testing}

Three LISST-ABS sensors were tested with a range of sediment concentrations created from three different types of sediment: a silt, a silt to very fine sand, and a fine sand (table 2). Certified sediment samples comprising varying ranges of particle size were purchased from Powder Technology Inc. These sediment samples were 30-80-micron ( $\mu \mathrm{m})$ Arizona Test Dust; less than 22- $\mu \mathrm{m}$ ISO 12103-1, A1 Ultrafine Test Dust; and 149- $\mu \mathrm{m}$ MIL-STD 810E Silica Dust (International Organization for Standardization, 1997; U.S. Department of Defense, 1989). Testing was conducted first at room temperatures for each sensor and then over an extended range of temperatures for two sensors. An open-top Chem-tainer 10-gallon (gal) tank, tank stand (part number [pn] TC1528AP, The Tank Depot), and electric mixer were used to mix and maintain the various calibration and sample sediment concentrations. The tank's cylindrical cone bottom was retrofitted with a drain tube and stopcock to allow easy draining of the tank contents. The mixer setup used an electric variable-speed 1/15th horsepower mixer (pn 34745K71, McMaster-Carr), a stand with a swivel connector (pn 35265K11, McMaster-Carr), a 4-inch (in.) stainless steel propeller (pn 8364T5, McMaster-Carr), a 12-in. stainless steel drive shaft (pn 8004K421, McMaster-Carr), and two pairs of mounting brackets (pn 1307T221, McMaster-Carr).

All calibration and sample SSCs were made by adding 25 liters (L) of tap water and carefully measured fractions of characterized sediment types to the 10-gallon mixing tank (fig. 2). The electric mixer was adjusted to maintain a good suspension of the sediment during calibration and sample testing of the ABS sensor. Measured fractions of characterized sediment were weighed on a Mettler AE200 digital scale accurate to 0.0001 gram (g) and were added to the mixing tank water to create the calibration and sample SSCs. Temperature of the mixing tank water was measured by a National Institute Standards and Technology-traceable YSI 4600 digital thermometer certified accurate to 0.1 degree Celsius $\left({ }^{\circ} \mathrm{C}\right)$. To change sensor and sample water temperatures for the extended temperature testing, the mixing tank, mixer, and ABS were placed inside a reach-in ESPEC environmental chamber (fig. 2).

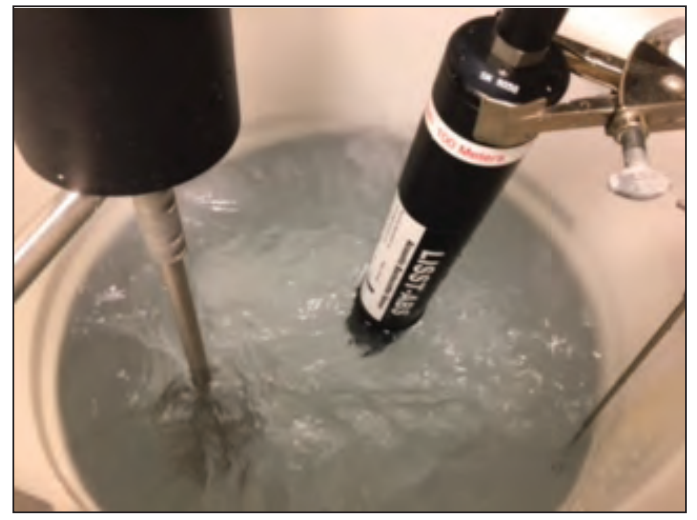

Figure 2. The LISST-ABS, electric mixer, and thermistor probe mounted in the mixing tank with 25 liters of water and characterized sediment. 
Each ABS sensor was calibrated with a 100-milligram-per-liter (mg/L) SSC of the selected calibration sediment type. To calculate the Cal Factor needed for calculated SSC, the ABS was submerged in the agitated 100-mg/L SSC calibration solution. Using the Sequoia Scientific LISST-ABS software, the "Recalibrate" option was selected, which opened a separate window to input the known SSC in milligrams per liter. Version 1.3 of the software specified the use of a 100-mg/L SSC solution, and this recommendation was adhered to for the evaluation. The software collects and averages measured uncalculated SSC readings for 1 minute and calculates the Cal Factor applicable to the sediment particle-size distribution of the solution. This value is sediment-size dependent and is not stored on the sensor. Sequoia Scientific (2016c) recommends the user record this value for future reference. This Cal Factor is applied to the uncalibrated SSC output, and calibrated SSC, in milligrams per liter, is displayed. This procedure was repeated each time a different sediment was used.

To obtain the most accurate results, the ABS was programmed to collect a 30-second average of 1-second sensor measurements (Sequoia Scientific, 2016c). The sample SSCs, temperatures, and turbidity values in formazin nephelometric units (FNUs) were recorded for each ABS-measured SSC. Sample SSCs were calculated from the weight of the cumulative added sediment fractions divided by the volume of mixing water $(25 \mathrm{~L})$. Testing results were determined by the percent difference between the measured and calculated SSC. Percent difference was determined by the following equation:

$$
\text { Percent difference }=100 \times \frac{\text { measured SSC in } m g / L-\text { calculated SSC in } m g / L}{\text { calculated SSC }\left(\frac{m g}{L}\right)}
$$

Because difference was determined by subtracting the calculated SSC from the measured SSC value, positive values indicated a high bias in the data, and negative values indicated a low bias.

In situ turbidity data are often used as a surrogate for estimated SSC in the environment. For this evaluation, turbidity of the test bath was used to not only validate the increasing SSC of the mixing tank water, but also served as a comparison for the relative response of the ABS in changing conditions. Turbidity of the clear water, and of the mixing tank water after the addition of subsequent fractions of sediment, was measured by a calibrated Hach $2100 \mathrm{~N}$ benchtop turbidimeter. The $2100 \mathrm{~N}$ was calibrated prior to use with ultrapure deionized water and StablCal 20, 200, 1,000, and 4,000 nephelometric turbidity unit (NTU) standards by following the calibration procedures detailed in the Hach $2100 \mathrm{~N}$ basic user manual (Hach, 2014).

Proper comparison of the ABS readings to the corresponding turbidity measurements required normalization of the data. To normalize the data, the measured responses of the ABS and of the turbidimeter in every SSC solution were divided by the instrument's "calibration response" in the 100-mg/L calibration solution. For example, the ABS-measured SSC was $104 \mathrm{mg} / \mathrm{L}$ in the $100-\mathrm{mg} / \mathrm{L}$ calibration bath, $158 \mathrm{mg} / \mathrm{L}$ in the $200-\mathrm{mg} / \mathrm{L} \mathrm{SSC}$ bath, and $193 \mathrm{mg} / \mathrm{L}$ in the $300-\mathrm{mg} / \mathrm{L} \mathrm{SSC}$ bath. The normalized values for the 100-, 200-, and 300-mg/L SSC solutions were 1 (104 mg/L divided by 104), 1.52 (158 mg/L divided by 104), and $1.86(193 \mathrm{mg} / \mathrm{L}$ divided by 104$)$. Repeating this process using the turbidity data gave the turbidity normalized values and simplified the process of comparing one type of data (measured in milligrams per liter) to a different type of data (measured in FNUs).

Test results for the initially tested sensor, serial number 6010, in a static SSC showed increasing measured SSC with decreasing temperatures, indicating that the sensor was either malfunctioning or inadequately compensated for temperature. The sensor was replaced by the vendor with sensor serial number 6039 and was subsequently tested. Also tested was sensor 6058, which was evaluated for the effect of dissimilar calibration/sample particle-size distribution. Test procedures and test results for each sensor are presented separately in the report.

Table 2. Sediment samples' aggregate classes, particle sizes, and particle-size distributions (Powder Technology Inc., 2015).

[ $\mu \mathrm{m}$, micrometer or micron]

\begin{tabular}{llcc}
\hline \multicolumn{1}{c}{ Sediment sample } & Aggregate class & Particle sizes, in $\mu \mathrm{m}$ & $\begin{array}{c}\text { Cumulative percent of } \\
\text { particle size }\end{array}$ \\
\hline ISO 12103-1, A1 Ultrafine Test Dust & Silt & $0.97-5.5$ & 67.7 \\
& & $0.97-11.0$ & 95.8 \\
Arizona Test Dust & & $0.97-22.0$ & 100 \\
& Silt to very fine sand & $5.60-9.87$ & 1.1 \\
& & $5.60-28.9$ & 8.3 \\
MIL-STD-810E Silica Dust & Fine sand & $5.60-85.1$ & 99.9 \\
\hline
\end{tabular}




\section{Test Procedures: Room-Temperature Testing of Sensor 6010}

Four tests on sensor 6010 were conducted at room temperature. For the first two tests, the accuracy of the ABS was evaluated in increasing, but static, particle-size distribution SSC values. For both tests, the ABS calculated the measured values for the intial SSCs of $0,10,50,75$, and $100 \mathrm{mg} / \mathrm{L}$ using the factory calibration based on a $63-75-\mu \mathrm{m}$ particle-size distribution (Sequoia Scientific, 2016c). After calibration with the sample sediment, SSCs of 100, 125, 150, 200, 250, 300, 350, 500, 750, $1,000,2,000,2,500$ and 3,000 mg/L were tested. For the first room-temperature test, the ISO 12103-1, A1 Ultrafine Test Dust was used as the sample sediment. The electric mixer was adjusted to maintain a velocity of approximately 1.5 feet per second $(\mathrm{ft} / \mathrm{s})$ during calibration and sample testing of the ABS sensor. For the second room-temperature test, the existing calibration for SSC less than $100 \mathrm{mg} / \mathrm{L}$ was based on the Ultrafine Test Dust from the previous test, and the Arizona Test Dust was used as the sample sediment. The initial setting of the electric mixer (to maintain approximately $1.5 \mathrm{ft} / \mathrm{s}$ ) was increased to prevent settling of the coarser particle-sized sediment during the second test.

The third and fourth room-temperature tests examined the effect of sand on the ABS calibration and SSC measurements. The effect of sand's larger particle-size distribution on fluvial suspended-sediment measurements has been well documented (Czuba and others, 2015). Accurate spatial and temporal measurements of suspended-sediment are often skewed high by the relatively large fraction size of sand, and traditionally the full distribution of sand has been difficult to account for in continuous measurements using acoustic sensors. To test this effect, $25 \mathrm{~L}$ of tap water was added to the mixing tank, and initial measurements of temperature, turbidity, and SSC were recorded. A 100-mg/L SSC solution was created by using ISO 12103-1, A1 Ultrafine Test Dust (table 2). The sensor retained the calibration information from a previous test with the Ultrafine Test Dust, so recalibration of the sensor was not needed. Temperature, turbidity, sample or calculated SSC, and measured SSC were recorded for the 100-mg/L solution. An equivalent amount of MIL-STD 810E Silica Dust was weighed and systematically added to the mixing tank, creating a 200-mg/L SSC solution. The ABS was not recalibrated for the change in the solution particle-size distribution, and temperature, turbidity, sample SSC, and measured SSC values were again recorded. Additional aliquots of the Silica Dust were added to the mixing tank to create SSC solutions of 300 and $400 \mathrm{mg} / \mathrm{L}$, and the resulting changes in turbidity, sample and measured SSCs, and temperature were recorded.

This test was repeated using the Arizona Test Dust $(30-80 \mu \mathrm{m})$ to create a 100-mg/L SSC calibration solution. Equivalent amounts of the Silica Dust were weighed and added to the mixing tank to create sample SSCs of 200, 300, and $400 \mathrm{mg} / \mathrm{L}$. The resulting changes in turbidity, sample SSC, measured SSC, and temperature were recorded during the test.

\section{Test Procedures: Extended Temperature Testing of Sensor 6010}

To test the effect of temperature on the ABS accuracy, a fresh 100-mg/L Arizona Test Dust suspension was created by adding $2.5 \mathrm{~g}$ of sediment to $25 \mathrm{~L}$ of water, and the ABS was recalibrated with the Arizona Test Dust solution. The mixing tank setup, complete with the water tank, electric mixer, ABS, and digital thermometer, was placed into a reach-in environmental chamber, and the chamber temperature was increased from approximately 5 to $40^{\circ} \mathrm{C}$ (fig. 3). The sample and measured SSCs were recorded during the test along with the temperature of the mixing tank water. Also noted during the test were the initial turbidity reading per the benchtop turbidimeter and the turbidities of periodically sampled aliquots of the test solution. This test was repeated the next day using the same mixing tank water and subsequently repeated twice to confirm the effect that temperature had on the sensor's measured SSC values.
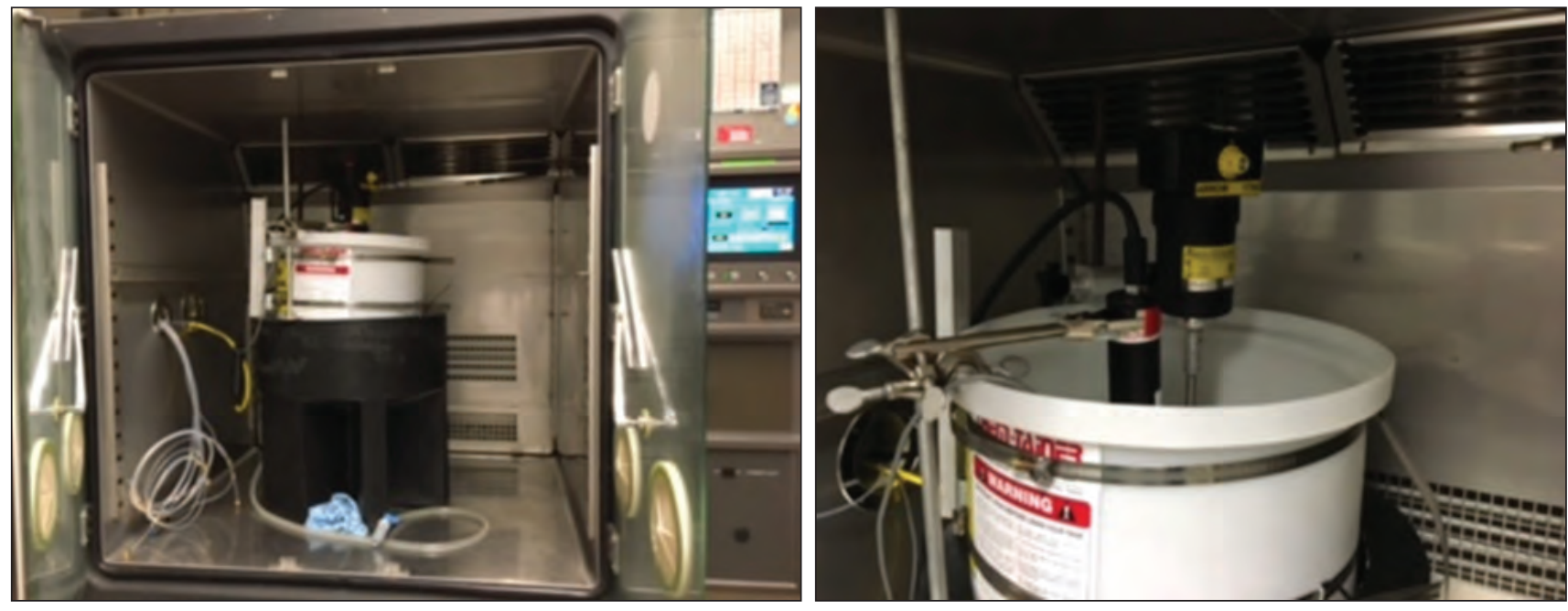

Figure 3. The test mixing tank setup containing the electric mixer and the LISST-ABS in the environmental chamber. 


\section{Test Results: Room-Temperature Testing of Sensor 6010}

The results from the room-temperature test with Ultrafine Test Dust are listed in table 3. The data for sample SSCs less than $100 \mathrm{mg} / \mathrm{L}$ were measured by using the factory calibration and were biased low. The sensor demonstrated good linear performance after calibration with a 100-mg/L SSC Ultrafine Test Dust solution, and data from 100 to 3,000 mg/L resulted in a maximum error of 15.0 percent. The theoretical linear response of the test, the proportional reponse of the LISST-ABS measured $\mathrm{SSC}$, and the corresponding turbidity measurements during the test are shown in figure 4.

The second room-temperature test evaluated the performance of the ABS in a larger particle size solution. The data for sample SSCs less than $100 \mathrm{mg} / \mathrm{L}$ were measured by using the Ultrafine Test Dust calibration from the previous test and were biased high due to the difference in particle-size distribution (table 4). Once calibrated for Arizona Test Dust, the sensor performed well in SSCs from 100 to 3,000 mg/L, with a maximum error of 10.9 percent. The linear and normalized reponse of the ABSmeasured SSC in the Arizona Test Dust solution as well as the corresponding turbidity measurements of the solution are shown in figure 5. The results from the first two room-temperature tests emphasize the need for a calibration that reflects the measured particle-size distribution.

Table 3. Sequoia Scientific LISST-ABS (serial number 6010) SSC measurements at room temperature in various concentrations of ISO 12103-1, A1 Ultrafine Test Dust with factory calibration and after calibration with ISO 12103-1, A1 Ultrafine Test Dust.

[g, gram; SSC, suspended-sediment concentration; mg/L, milligrams per liter; FNU, formazin nephelometric units; n/a, not applicable; >, greater than. Room temperature was 21 degrees Celsius. ISO 12103-1, A1 Ultrafine Test Dust has a particle size range of 1-22 microns]

\begin{tabular}{|c|c|c|c|c|c|}
\hline $\begin{array}{l}\text { Added sediment } \\
\text { fraction }(\mathrm{g})\end{array}$ & $\begin{array}{l}\text { Turbidity } \\
\text { (FNU) }\end{array}$ & $\begin{array}{c}\text { Calibration } \\
\text { sediment }\end{array}$ & $\begin{array}{c}\text { Sample SSC } \\
(\mathrm{mg} / \mathrm{L})\end{array}$ & $\begin{array}{c}\text { Measured SSC } \\
(\mathrm{mg} / \mathrm{L})\end{array}$ & $\begin{array}{c}\text { Percent } \\
\text { difference }\end{array}$ \\
\hline 0.25 & 5.36 & \multirow{4}{*}{ factory (63-75 micron) } & 10 & 2.42 & -75.8 \\
\hline 1.02 & 28.9 & & 50 & 4.89 & -90.2 \\
\hline 0.6 & 42.3 & & 75 & 5.38 & -92.8 \\
\hline 0.61 & 56.7 & & 100 & 14.4 & -85.6 \\
\hline $\mathrm{n} / \mathrm{a}$ & 56 & \multirow{14}{*}{ Ultrafine Test Dust } & 100 & 115 & 15 \\
\hline 0.68 & 74 & & 125 & 125 & 0 \\
\hline 0.64 & 90.7 & & 150 & 153 & 2 \\
\hline 1.2 & 121 & & 200 & 206 & 3 \\
\hline 1.25 & 156 & & 250 & 235 & -6 \\
\hline 1.25 & 188 & & 300 & 329 & 9.7 \\
\hline 1.25 & 220 & & 350 & 388 & 10.9 \\
\hline 3.75 & 345 & & 500 & 496 & -0.8 \\
\hline 6.25 & 562 & & 750 & 783 & 4.4 \\
\hline 6.24 & 865 & & 1,000 & 1,061 & 6.1 \\
\hline 12.5 & 1,723 & & 1,500 & 1,539 & 2.6 \\
\hline 12.5 & 2,689 & & 2,000 & 1,819 & -9.1 \\
\hline 12.5 & 3,557 & & 2,500 & 2,687 & 7.5 \\
\hline 12.5 & $>4,000^{1}$ & & 3,000 & 3,220 & 7.3 \\
\hline
\end{tabular}

\footnotetext{
${ }^{1}$ Exceeded upper range of Hach $2100 \mathrm{~N}$ turbidimeter calibration (4,000 FNU).
} 


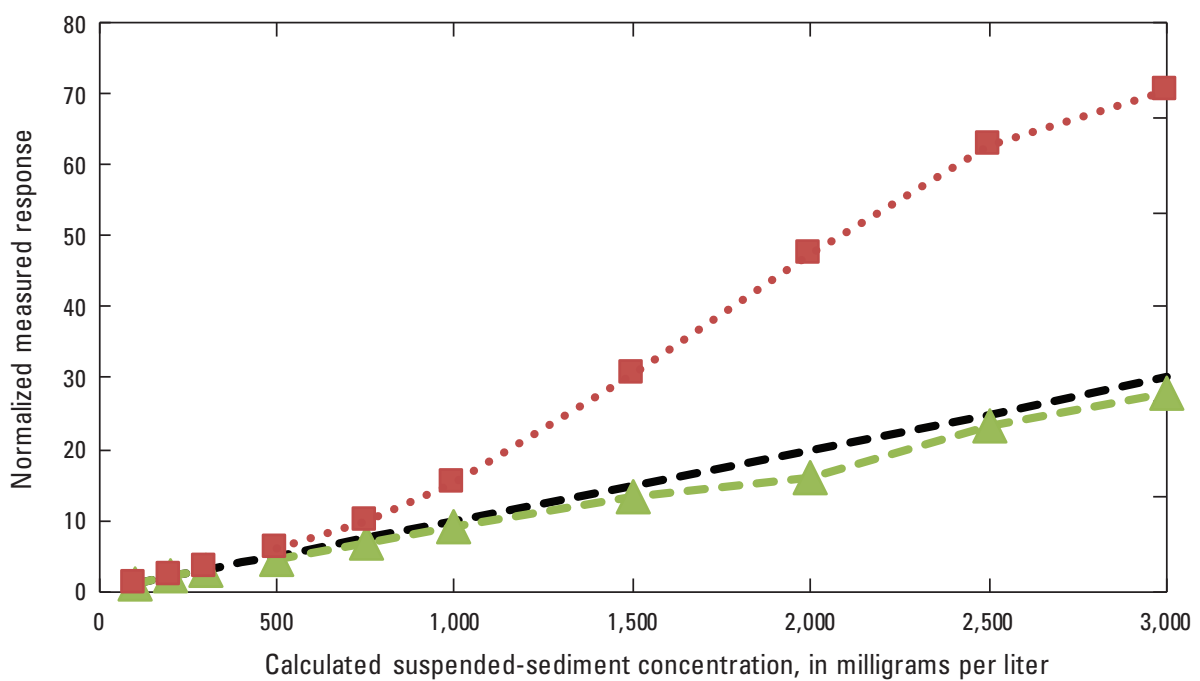

EXPLANATION

- - Theoretical linear response

- Serial number 6010 normalized response in ISO 12103-1 A1 Ultrafine Test Dust after calibration with IS0 12103-1 A1 Ultrafine Test Dust

.. . . Turbidimeter response for serial number 6010 test

Figure 4. The theoretical linear and normalized measured response of the Sequoia Scientific LISST-ABS (serial number 6010) to increasing ISO 12103-1, A1 Ultrafine Test Dust suspended-sediment concentration after calibration with 12103-1, A1 Ultrafine Test Dust. Also shown are the normalized responses of the Hach $2100 \mathrm{~N}$ benchtop turbidimeter.

Table 4. Sequoia Scientific LISST- ABS (serial number 6010) SSC measurements at room temperature in various concentrations of Arizona Test Dust after calibration with ISO 12103-1 A1 Ultrafine Test Dust and after calibration with Arizona Test Dust.

[g, gram; SSC, suspended-sediment concentration; mg/L, milligrams per liter; FNU, formazin nephelometric units; n/a, not applicable; >, greater than. Room temperature was 21 degrees Celsius. Arizona Test Dust has a particle size range of 30-80 microns. ISO 12103-1, A1 Ultrafine Test Dust has a particle size range of 1-22 microns]

\begin{tabular}{cccccc}
\hline $\begin{array}{c}\text { Added sediment } \\
\text { fraction (g) }\end{array}$ & $\begin{array}{c}\text { Turbidity } \\
\text { (FNU) }\end{array}$ & $\begin{array}{c}\text { Calibration } \\
\text { sediment }\end{array}$ & $\begin{array}{c}\text { Sample SSC } \\
\text { (mg/L) }\end{array}$ & $\begin{array}{c}\text { Measured SSC } \\
\text { (mg/L) }\end{array}$ & $\begin{array}{c}\text { Percent } \\
\text { difference }\end{array}$ \\
\hline 0.25 & 0.29 & & 10 & 87 & 770 \\
1 & 4.2 & Ultrafine Test Dust & 50 & 1,378 & 2,656 \\
0.61 & 5.84 & 75 & 2,008 & 1,933 \\
0.63 & 8.96 & & 100 & 2,399 & 2,299 \\
\hline $\mathrm{n} / \mathrm{a}$ & 8.98 & 100 & 109 & 9 \\
0.64 & 90.7 & & 150 & 153 & 2 \\
1.2 & 121 & 200 & 206 & -6 \\
1.25 & 156 & 250 & 235 & 9.7 \\
1.25 & 188 & & 300 & 329 & 10.9 \\
1.25 & 220 & 350 & 388 & -0.8 \\
3.75 & 345 & 500 & 496 & 4.4 \\
6.25 & 562 & Arizona Test Dust & 750 & 783 & 6.1 \\
6.24 & 865 & & 1,000 & 1,061 & 2.6 \\
12.5 & 1,723 & 1,500 & 1,539 & -9.1 \\
12.5 & 2,689 & 2,000 & 1,819 & 7.5 \\
12.5 & 3,557 & 2,500 & 2,687 & 7.3 \\
12.5 & $1>4,000$ & 3,000 & 3,220 & \\
\hline
\end{tabular}

${ }^{1}$ Exceeded upper range of Hach $2100 \mathrm{~N}$ turbidimeter calibration (4,000 FNU). 


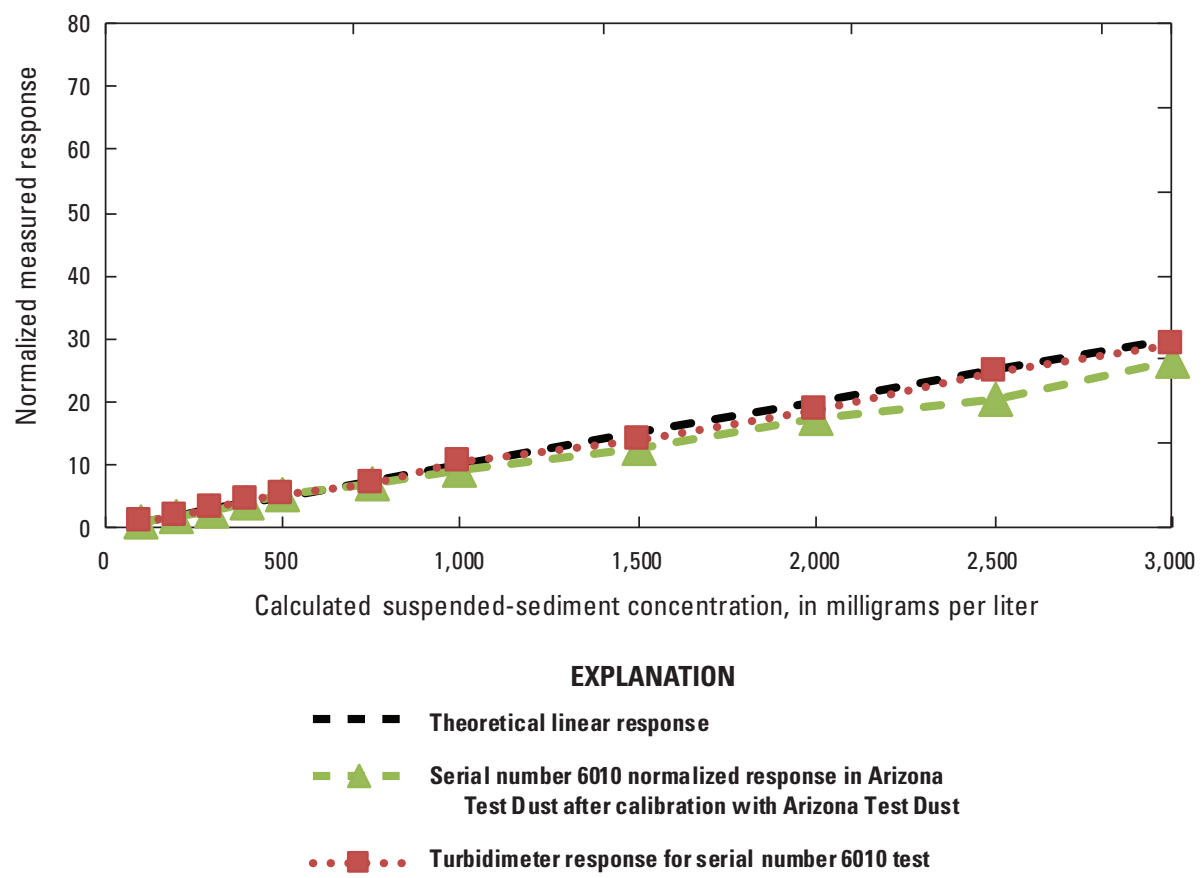

Figure 5. The theoretical linear and normalized measured response of the Sequoia Scientific LISST-ABS (serial number 6010) to increasing Arizona Test Dust suspended-sediment concentrations, after calibration with Arizona Test Dust. Also shown as red squares are the normalized responses of the Hach $2100 \mathrm{~N}$ benchtop turbidimeter in comparison.

The third and fourth room-temperature tests evaluated the effect of Silica Dust on sensor accuracy. For the third test, a fresh 100-mg/L Ultrafine Test Dust solution was created, and the initial sample and measured SSC, temperature, and turbidity were recorded. Measured fractions of MIL-STD-810E Silica Dust were added to produce a 1:1, 1:2, and 1:3 Ultrafine Test Dust to Silica Dust SSC solution. The resulting sample and measured SSC, temperature, and turbidity values are listed in table 5 along with percent difference. The theoretical linear and normalized response of sensor 6010 to the increasing amounts of Silica Dust and the corresponding turbidity measurements for each SSC are shown in figure 6. Surprisingly, for this sensor, the addition of the much coarser Silica Dust to the Ultrafine Test Dust solution had little effect on sensor accuracy.

Table 5. Sequoia Scientific LISST- ABS (serial number 6010) SSC measurements in increasing proportions of MIL-STD-810E Silica Dust to ISO 12103-1, A1 Ultrafine Test Dust after calibration with ISO 12103-1, A1 Ultrafine Test Dust at room temperature.

[g, gram; SSC, suspended-sediment concentration; mg/L, milligram per liter; FNU, formazin nephelometric units; $\mathrm{n} / \mathrm{a}$, not applicable. Room temperature was 19 degrees Celsius. MIL-STD-810E Silica Dust has a particle size of 143 microns. ISO 12103-1, A1 Ultrafine Test Dust has a particle size range of $1-22$ microns]

\begin{tabular}{ccccccc}
\hline $\begin{array}{c}\text { Added fraction } \\
(\mathbf{g})\end{array}$ & Added sediment & $\begin{array}{c}\text { Calibration to added } \\
\text { sediment ratio }\end{array}$ & $\begin{array}{c}\text { Turbidity } \\
\text { (FNU) }\end{array}$ & $\begin{array}{c}\text { Sample SSC } \\
\text { (mg/L) }\end{array}$ & $\begin{array}{c}\text { Measured SSC } \\
\text { (mg/L) }\end{array}$ & $\begin{array}{c}\text { Percent } \\
\text { difference }\end{array}$ \\
\hline 0 & none & n/a & 0.34 & 0 & 3.6 & $\mathrm{n} / \mathrm{a}$ \\
2.50 & Ultrafine Test Dust & (calibration) & 57.6 & 100 & 101 & 1.0 \\
2.51 & Silica Dust & $1: 1$ & 84.4 & 200 & 210 & 3.0 \\
2.50 & Silica Dust & $1: 2$ & 118.6 & 300 & 419 & 416 \\
2.50 & Silica Dust & $1: 3$ & 136 & 400 & 4.0 \\
\hline
\end{tabular}




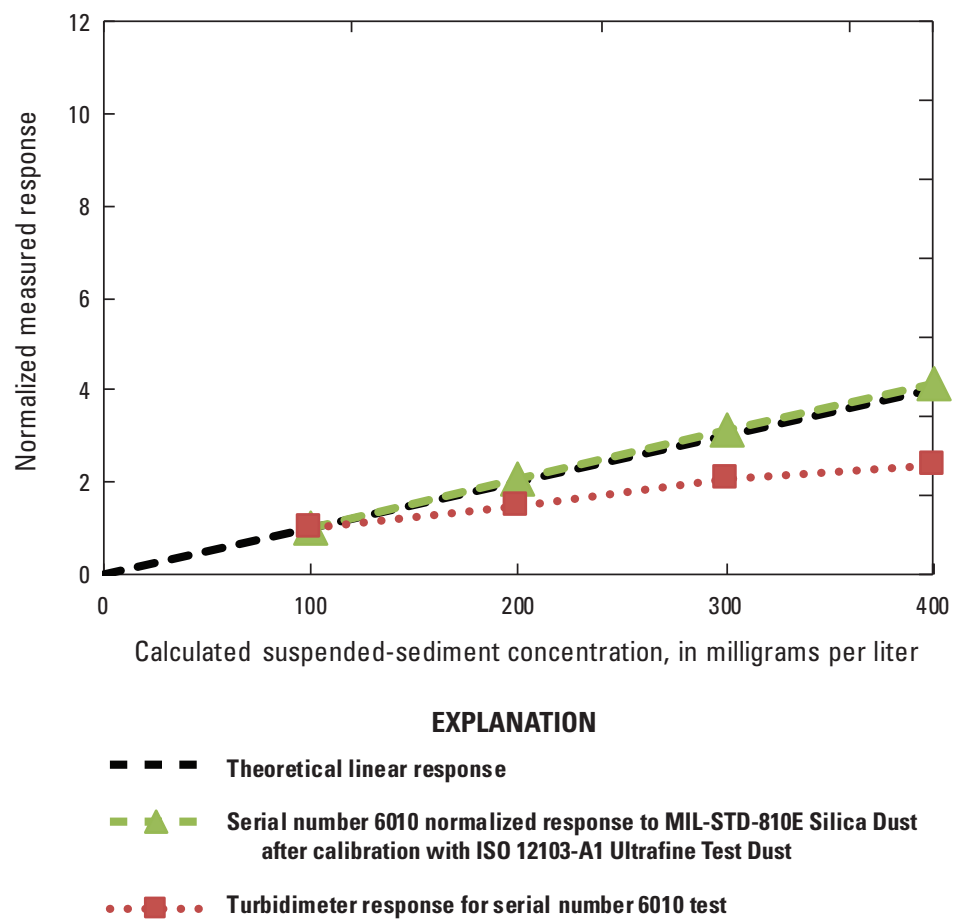

Figure 6. The theoretical linear and normalized measured response of the Sequoia Scientific LISST-ABS (serial number 6010) and the resulting suspended-sediment concentrations to additions of MIL-STD-810E Silica Dust after calibration with ISO 12103-1, A1 Ultrafine Test Dust. Also shown as red squares are the normalized responses of the Hach $2100 \mathrm{~N}$ benchtop turbidimeter in comparison.

The fourth test evaluated the effect of Silica Dust on the ABS calibrated for Arizona Test Dust. Similar to the Ultrafine/ Silica test, subsequent fractions of MIL-STD-810E Silica Dust were weighed and added to produce a 1:1, 1:2, and 1:3 Arizona Test Dust to Silica Dust SSC mixing tank water. Also similar to the Ultrafine/Silica test, the ABS was not recalibrated after the addition of the Silica Test Dust. Sample SSC, measured SSC, temperature, turbidity, and percent difference between sample and measured SSC are listed in table 6. The normalized response of sensor 6010 to the increasing amounts of Silica Dust as compared to the theoretical linear response, and the corresponding normalized turbidity data for each solution are shown in figure 7. Data from sensor 6010 showed a "flattened" response with the addition of silica to the Arizona Test Dust sediment suspension, and had a maximum difference of -46.5 percent in the $400-\mathrm{mg} / \mathrm{L}$ sample concentration.

Table 6. Sequoia Scientific LISST- ABS (serial number 6010) SSC measurements in increasing proportions of MIL-STD-810E Silica Dust to Arizona Test Dust after calibration with Arizona Test Dust.

[g, gram; SSC, suspended-sediment concentration; mg/L, milligrams per liter; FNU, formazin nephelometric units; n/a, non applicable. MIL-STD-810E Silica Dust has a 143-micron particle size. Arizona Test Dust has a particle size range of 30-80 microns]

\begin{tabular}{ccccccc}
\hline $\begin{array}{c}\text { Added fraction } \\
(\mathbf{g})\end{array}$ & Added sediment & $\begin{array}{c}\text { Calibration to added } \\
\text { sediment ratio }\end{array}$ & $\begin{array}{c}\text { Turbidity } \\
\text { (FNU) }\end{array}$ & $\begin{array}{c}\text { Sample SSC } \\
\text { (mg/L) }\end{array}$ & $\begin{array}{c}\text { Measured SSC } \\
\text { (mg/L) }\end{array}$ & $\begin{array}{c}\text { Percent } \\
\text { difference }\end{array}$ \\
\hline 0 & none & n/a & 0.35 & 0 & 1.19 & $\mathrm{n} / \mathrm{a}$ \\
2.50 & Arizona Test Dust & (calibration) & 8.05 & 100 & 4.0 & 104 \\
2.50 & Silica Dust & $1: 1$ & 34.3 & 200 & 158 & -21.0 \\
2.51 & Silica Dust & $1: 2$ & 68.0 & 300 & -35.7 \\
2.51 & Silica Dust & $1: 3$ & 99.2 & 400 & 214 & -46.5 \\
\hline
\end{tabular}




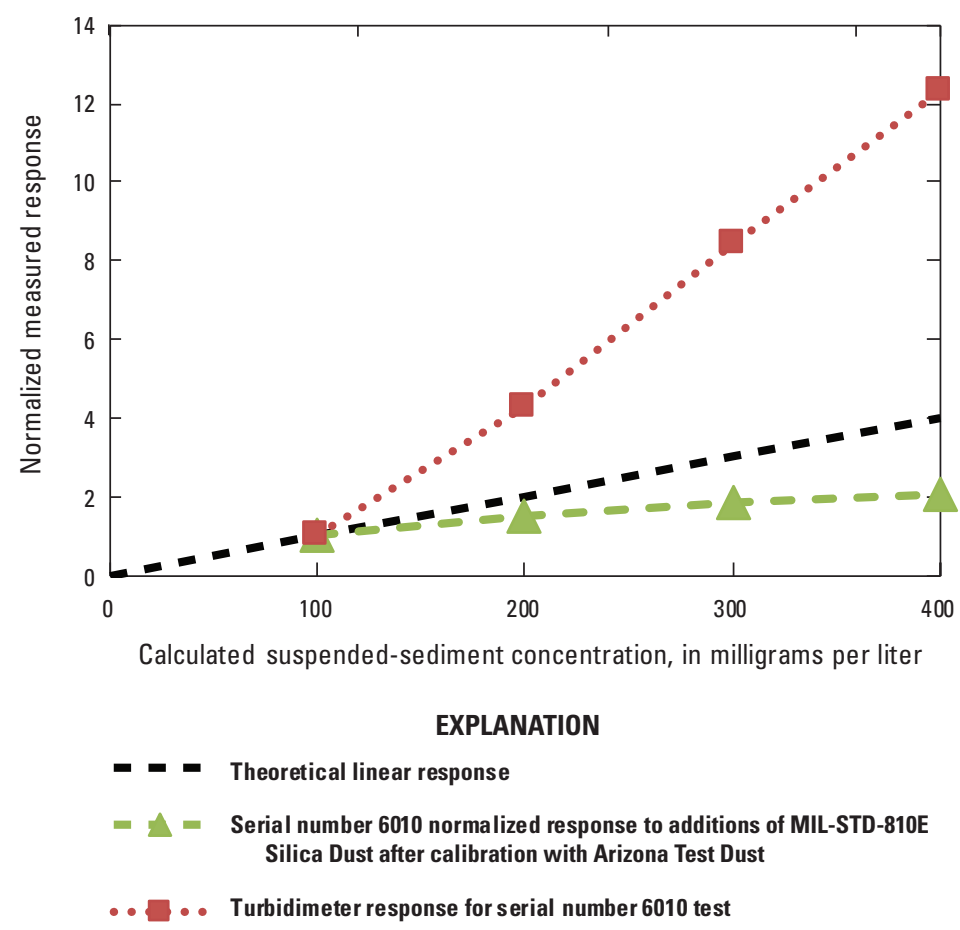

Figure 7. The theoretical linear and normalized measured response of sensor 6010, and the resulting suspended-sediment concentrations to additions of MIL-STD-810E Silica Dust after calibration with Arizona Test Dust. Also shown as red squares are the normalized responses of the Hach $2100 \mathrm{~N}$ benchtop turbidimeter in comparison.

\section{Test Results: Extended Temperature Testing of Sensor 6010}

The ABS measures backscatter from a point approximately $5.5 \mathrm{~cm}$ from the transducer. This short path length is used so that changes in water temperature will be insignificant in the sensor's computation of SSC and calibration at measurement temperatures will be unnecessary. To verify this, the ABS was once again subjected to a 100-mg/L SSC of Arizona Test Dust and tap water. The ABS was not recalibrated because the stored calibration was for the identical SSC solution. The mixing tank described in the test procedures section was placed into a programmed environmental chamber. Initial tests showed good correlation between the sample and measured SSCs, but as the water temperature was lowered from an initial $19.92{ }^{\circ} \mathrm{C}$ to a low of $3.84{ }^{\circ} \mathrm{C}$, the measured SSC increased substantially. Raising the temperature from room temperature to a high of $35.35{ }^{\circ} \mathrm{C}$ produced an inverse reaction, and the measured SSC was substantially reduced (table 7). Turbidity of the solution was checked initially by using the benchtop turbidimeter and sporadically throughout the test to verify that the mixing tank water remained unchanged. The temperature test was repeated the next day to focus on the effect of lower temperatures without altering the test set up, using the same $100 \mathrm{mg} / \mathrm{L}$ solution, and the same environmental chamber. The results from this limited lowered-temperature test are listed in table 8 .

The temperature test was repeated a third time with a fresh 100-mg/L Arizona Test Dust solution, using the same environmental chamber. The initial SSC of the mixing tank water at $20.12^{\circ} \mathrm{C}$ was $99.3 \mathrm{mg} / \mathrm{L}$. The water temperature was slowly reduced from the starting temperature $\left(20.12{ }^{\circ} \mathrm{C}\right)$ to a low of $6.93{ }^{\circ} \mathrm{C}$, and then returned to room temperature while the measured SSC values were collected. The measured SSC increased from the initial value $(99.3 \mathrm{mg} / \mathrm{L})$ to a high of $399.8 \mathrm{mg} / \mathrm{L}$ at approximately $7{ }^{\circ} \mathrm{C}$ (fig. 8). The results of this test clearly demonstrate clearly the effect of temperature on ABS sensor 6010 . Sensor 6010 was sent to the vendor for repair and was replaced with sensor 6039. 
Table 7. Sequoia Scientific LISST-ABS (serial number 6010) SSC measurements and percent difference from sample concentration in $100-\mathrm{mg} / \mathrm{L}$ concentration of Arizona Test Dust (30-80-micron particle size) at various temperatures during an initial test.

[SSC, suspended-sediment concentration; mg/L, milligram per liter; ${ }^{\circ} \mathrm{C}$, degrees Celsius, $\mathrm{FNU}$, formazin nephelometric units]

\begin{tabular}{ccccc}
\hline $\begin{array}{c}\text { Sample SSC } \\
(\mathbf{m g} / \mathbf{L})\end{array}$ & $\begin{array}{c}\text { Turbidity } \\
(\mathbf{F N U})\end{array}$ & $\begin{array}{c}\text { Temperature } \\
\left({ }^{\circ} \mathbf{C}\right)\end{array}$ & $\begin{array}{c}\text { Measured SSC } \\
(\mathbf{m g} / \mathbf{L})\end{array}$ & $\begin{array}{c}\text { Percent } \\
\text { difference }\end{array}$ \\
\hline 100 & 8.06 & 19.81 & 101 & 1.0 \\
100 & & 8.07 & 308 & 208 \\
100 & & 6.65 & 389 & 289 \\
100 & & 3.83 & 367 & 267 \\
100 & 7.10 & 11.24 & 87.2 & -12.8 \\
100 & & 11.68 & 68.0 & -32.0 \\
100 & & 12.27 & 106 & 6.0 \\
100 & & 29.16 & 77.3 & -22.7 \\
100 & & 29.41 & 26.5 & -73.5 \\
100 & 7.28 & 33.3 & 34.4 & -65.6 \\
100 & & 35.35 & 33.2 & -66.8 \\
100 & & 35.30 & 35.3 & -64.7 \\
\hline
\end{tabular}

Table 8. Sequoia Scientific LISST-ABS (serial number 6010) SSC measurements and percent difference from sample concentration in $100-\mathrm{mg} / \mathrm{L}$ concentration of Arizona Test Dust (30-80-micron particle size) at various temperatures during a repeated lower temperature test.

[SSC, suspended-sediment concentration; mg/L, milligram per liter; ${ }^{\circ} \mathrm{C}$, degrees Celsius, FNU, formazin nephelometric units]

\begin{tabular}{ccccc}
\hline $\begin{array}{c}\text { Sample SSC } \\
(\mathbf{m g} / \mathbf{L})\end{array}$ & $\begin{array}{c}\text { Turbidity } \\
\text { (FNU) }\end{array}$ & $\begin{array}{c}\text { Temperature } \\
\left({ }^{\circ} \mathbf{C}\right)\end{array}$ & $\begin{array}{c}\text { Measured SSC } \\
(\mathbf{m g} / \mathbf{L})\end{array}$ & $\begin{array}{c}\text { Percent } \\
\text { difference }\end{array}$ \\
\hline 100 & 7.32 & 20.04 & 108 & 8.0 \\
100 & & 9.41 & 334 & 334 \\
100 & & 9.37 & 474 & 474 \\
100 & & 7.70 & 284 & 284 \\
100 & 7.56 & 7.66 & 298 & 298 \\
\hline
\end{tabular}

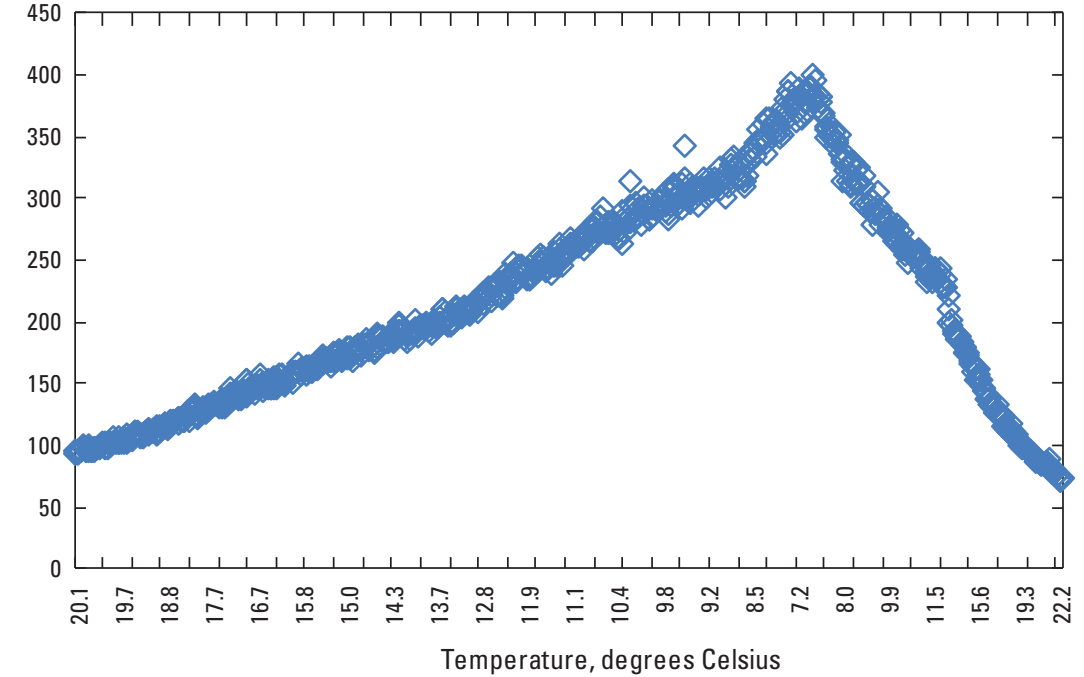

Figure 8. The collective results from three temperature tests of sensor 6010 showing the effect of varying temperatures on measured suspended-sediment concentration (SSC) of a 100-milligram-perliter (mg/L) Arizona Test Dust solution. 


\section{Test Procedures: Room-Temperature Testing of Sensor 6039}

Like sensor 6010, sensor 6039 was also tested to determine the effect of coarser particle size Silica Dust on a calibration based on Ultrafine Test Dust. For this test, sensor 6039 was calibrated with a 100-mg/L SSC Ultrafine Test Dust solution, and temperature, turbidity, sample SSC, and measured SSC were recorded. MIL-STD-810E Silica Dust was weighed and systematically added to the mixing tank, creating solutions of $200-500 \mathrm{mg} / \mathrm{L}$, and the resulting changes in turbidity and sample and measured SSCs were recorded along with temperature. The ABS sensor was not recalibrated for the changes in the particle-size distribution of the solution.

Sensor 6039 was also calibrated with a 100-mg/L SSC Silica Dust (MIL-STD 810E) solution. To test the effect of finer sized particles on a calibration based on a coarser particle-sized distribution, Ultrafine Test Dust was systematically added to the mixing tank containing the initial calibration solution, creating sample SSCs of $200-500 \mathrm{mg} / \mathrm{L}$. The resulting changes in turbidity and sample and measured SSC were recorded along with temperature. Again, the ABS was not recalibrated to reflect the changes in particle-size distribution that occurred with each addition of the Ultrafine Test Dust.

A calibration test sample was created consisting of a mix of three ranges of particle size. This HIF test mix was composed of 50 percent Arizona Test Dust $(30-80 \mu \mathrm{m}), 25$ percent Ultrafine Test Dust $(1-22 \mu \mathrm{m})$, and 25 percent Silica Dust $(149 \mu \mathrm{m})$ (fig. 9). Two separate room-temperature tests were conducted to evaluate the effect of finer particle-sized sediment (Ultrafine Test Dust) and coarser sediment (Silica Dust) on a calibration based upon this test mix. The resulting changes in turbidity and sample and measured SSC were recorded along with water temperature.

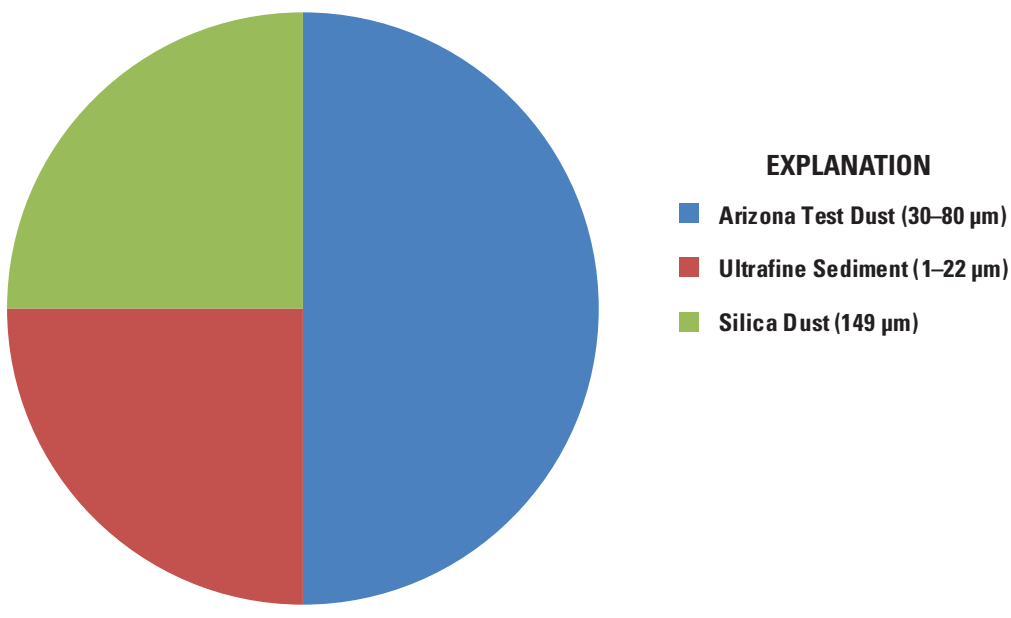

Figure 9. The composition of the HIF test mix used in calibration testing of Sequoia Scientific LISST-ABS (sensor 6039).

\section{Test Procedures: Extended Temperature Testing of Sensor 6039}

To test Sequoia Scientific's remediation of the ABS temperature compensation issue, sensor 6039 was calibrated and tested in a fresh $100-\mathrm{mg} / \mathrm{L}$ Arizona Test Dust suspension over a range of temperatures. The solution was created by adding approximately $2.5 \mathrm{~g}$ of sediment to $25 \mathrm{~L}$ of water. The mixing tank setup, complete with the water tank, electric mixer, ABS, and digital thermometer, was placed into the environmental chamber, and the chamber temperature was again increased from approximately 5 to $40{ }^{\circ} \mathrm{C}$.

The sample and measured SSCs were recorded during the test, and the temperature of the sample water was recorded by a calibrated digital thermometer. Turbidity of the test solution was measured by the $2100 \mathrm{~N}$ benchtop turbidimeter and was monitored during testing with periodically sampled aliquots of the test solution. 


\section{Test Results: Room-Temperature Testing of Sensor 6039}

Measured fractions of MIL-STD-810E Silica Dust were added to produce 1:1, 1:2, 1:3, and 1:4 Ultrafine to Silica Dust SSC solutions. The resulting sample and measured SSC, temperature, turbidity, and percent difference between the sample and measured values are listed in table 9. Figure 10 shows the theoretical linear and proportional response of sensor 6039 with an Ultrafine Test Dust calibration to increasing proportions of Silica Dust to the Ultrafine Test Dust calibration solution. Unlike sensor 6010 (table 5), for sensor 6039, the addition of the much coarser silica to the ultrafine sediment suspension had a significant effect on the measurement accuracy and produced a significantly biased high response when compared to the response of the benchtop turbidimeter.

Table 9. Sequoia Scientific LISST-ABS (serial number 6039) SSC measurements showing the effect of MIL-STD-810E Silica Dust on the ISO 12103-1, A1 Ultrafine Test Dust calibration.

[g, gram; SSC, suspended-sediment concentration; mg/L, milligram per liter; FNU, formazin nephelometric units; n/a, not applicable]

\begin{tabular}{ccccccc}
\hline $\begin{array}{c}\text { Added fraction } \\
(\mathbf{g})\end{array}$ & Added sediment & $\begin{array}{c}\text { Calibration to added } \\
\text { sediment ratio }\end{array}$ & $\begin{array}{c}\text { Turbidity } \\
(\mathbf{F N U})\end{array}$ & $\begin{array}{c}\text { Sample SSC } \\
(\mathbf{m g} / \mathbf{L})\end{array}$ & $\begin{array}{c}\text { Measured SSC } \\
(\mathbf{m g} / \mathbf{L})\end{array}$ & $\begin{array}{c}\text { Percent } \\
\text { difference }\end{array}$ \\
\hline 0 & none & n/a & 0.34 & 0 & 3.6 & $\mathrm{n} / \mathrm{a}$ \\
2.49 & Ultrafine Test Dust & (calibration) & 63.8 & 100 & 104 & 4 \\
2.49 & Silica Dust & $1: 1$ & 94.5 & 200 & 518 & 159 \\
2.52 & Silica Dust & $1: 2$ & 124 & 300 & 1,009 & 236.3 \\
2.55 & Silica Dust & $1: 3$ & 163 & 400 & 1,254 & 213.5 \\
2.51 & Silica Dust & $1: 4$ & 193 & 500 & 2,012 & 302.4 \\
\hline
\end{tabular}

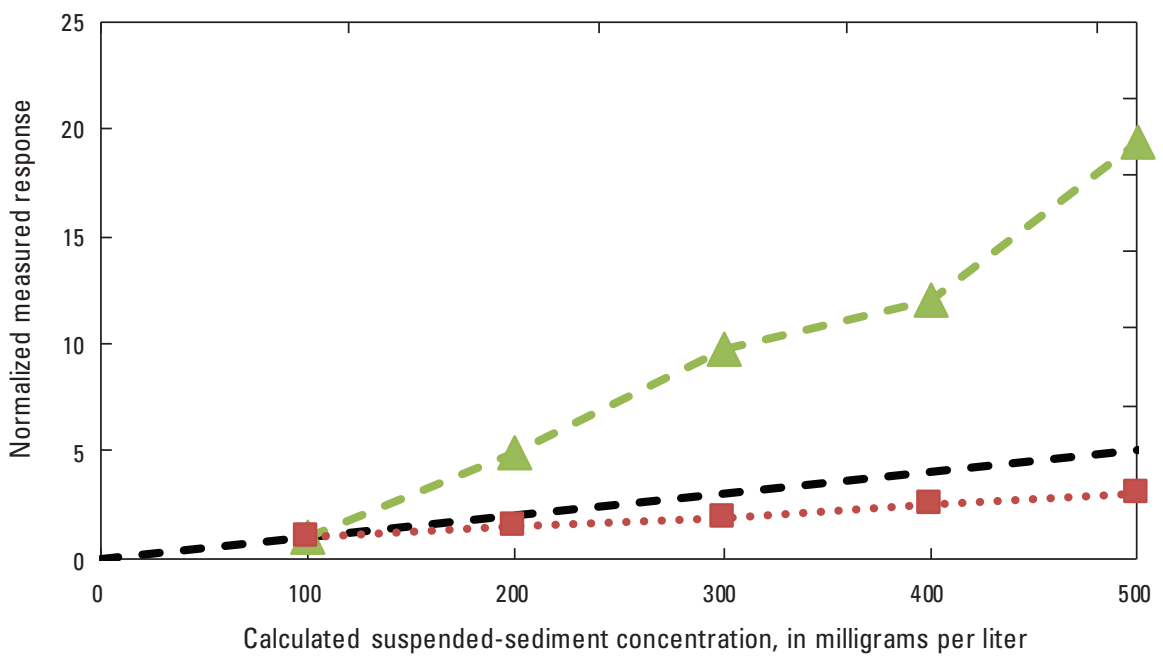

EXPLANATION

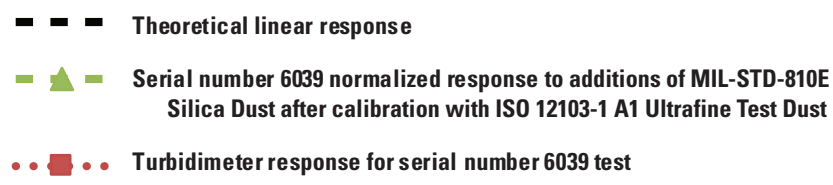

Figure 10. The theoretical linear and normalized response of sensor 6039, and the resulting suspended-sediment concentration to additions of MILSTD-810E Silica Dust, after calibration with ISO 12103-1, A1 Ultrafine Test Dust. Also shown as red squares are the normalized responses of the Hach $2100 \mathrm{~N}$ benchtop turbidimeter in comparison. 
An inverse effect was observed when the sensor was calibrated with the coarser Silica Dust and used to measure increasing fractions of the Ultrafine Test Dust in the original calibration solution (table 10). The additions of Ultrafine Test Dust to the Silica Dust suspended-sediment solution were not "registered" by the ABS as seen in the measured SSCs (fig. 11). In this test, the additions of the smaller particle-size fractions of Ultrafine Test Dust (silt) were not effectively measured by the ABS.

Table 10. Sequoia Scientific LISST-ABS (serial number 6039) SSC measurements showing the effect of ISO 12103-1, A1 Ultrafine Test Dust on the MIL-STD-810E Silica Dust calibration.

[g, gram; SSC, suspended-sediment concentration; mg/L, milligram per liter; FNU, formazin nephelometric units; n/a, not applicable]

\begin{tabular}{|c|c|c|c|c|c|c|}
\hline $\begin{array}{l}\text { Added fraction } \\
\text { (g) }\end{array}$ & Added sediment & $\begin{array}{l}\text { Calibration to added } \\
\text { sediment ratio }\end{array}$ & $\begin{array}{l}\text { Turbidity } \\
\text { (FNU) }\end{array}$ & $\begin{array}{l}\text { Sample SSC } \\
(\mathrm{mg} / \mathrm{L})\end{array}$ & $\begin{array}{c}\text { Measured SSC } \\
(\mathrm{mg} / \mathrm{L})\end{array}$ & $\begin{array}{l}\text { Percent } \\
\text { difference }\end{array}$ \\
\hline 0 & none & $\mathrm{n} / \mathrm{a}$ & 0.48 & 0 & 4.2 & $\mathrm{n} / \mathrm{a}$ \\
\hline 2.52 & Ultrafine Test Dust & $1: 1$ & 94.9 & 200 & 89.8 & -55.1 \\
\hline 2.49 & Ultrafine Test Dust & $1: 2$ & 170 & 300 & 101 & -66.3 \\
\hline
\end{tabular}

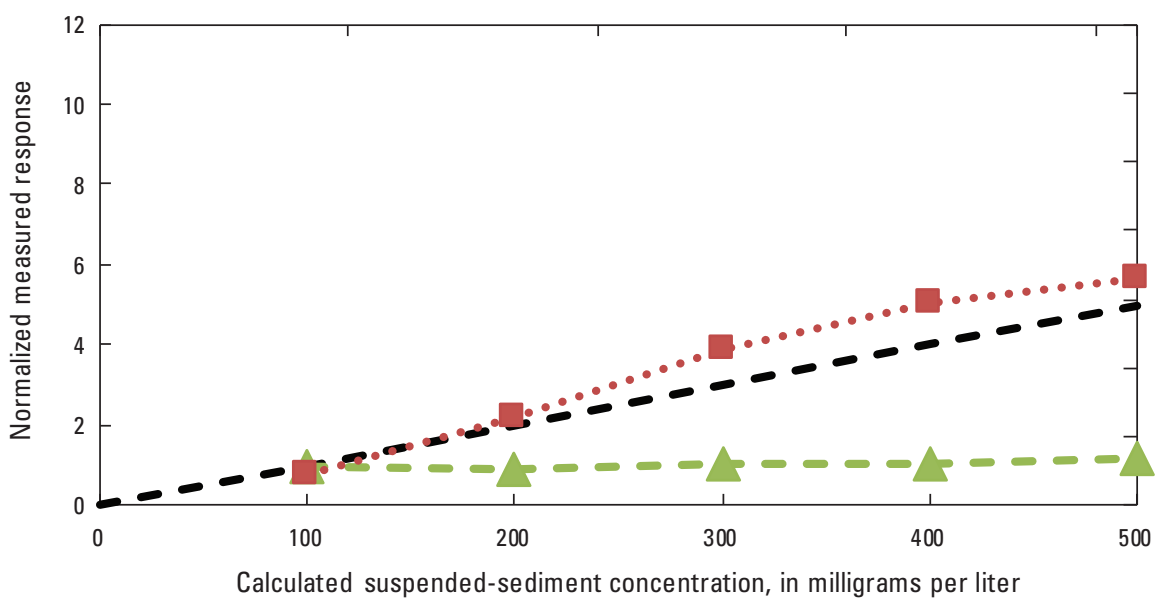

EXPLANATION

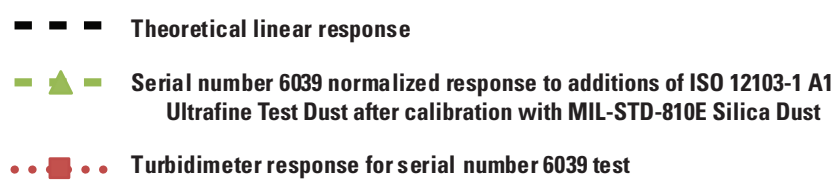

Figure 11. Theoretical linear and normalized response of sensor 6039, and the resulting suspended-sediment concentration to additions of ISO 12103-1, A1 Ultrafine Test Dust, after calibration with MIL-STD-810E Silica Dust. Also shown as red squares are the normalized responses of the Hach $2100 \mathrm{~N}$ benchtop turbidimeter in comparison. 
Test results from the HIF test mix calibration showed similar results to those seen in figure 11 when tested with the Ultrafine Test Dust. The increase in sample SSC was not reflected in the measured SSC values as indicated by the -78.6 percent maximum difference. The addition of smaller particle-size fractions of dust to the HIF test mix calibration were not registered by the sensor. Additional fractions of the Arizona Test Dust to the calibration based upon a 50 percent ratio of Arizona Test Dust produced the best results of the evaluation, with a maximum difference of 45.8 percent (table 11; fig. 12).

Table 11. Sequoia Scientific LISST-ABS (serial number 6039) SSC measurements showing the effect of ISO 12103-1, A1 Ultrafine Test Dust and Arizona Test Dust on the HIF test mix calibration.

\begin{tabular}{ccccc}
\hline $\begin{array}{c}\text { [SSC, suspended-sediment concentration; mg/L, milligram per liter] } \\
\text { Sample SSC } \\
\text { (mg/L) }\end{array}$ & $\begin{array}{c}\text { Measured SSC } \\
\text { with Ultrafine } \\
\text { Dust fractions } \\
\text { (mg/L) }\end{array}$ & $\begin{array}{c}\text { Percent } \\
\text { difference }\end{array}$ & $\begin{array}{c}\text { Measured SSC } \\
\text { with Arizona } \\
\text { Dust fractions } \\
\text { (mg/L) }\end{array}$ & $\begin{array}{c}\text { Percent } \\
\text { difference }\end{array}$ \\
\hline 100 & 100 & 0 & 106 & 6.0 \\
200 & 104 & -48.0 & 236 & 18.0 \\
300 & 121 & -59.7 & 412 & 37.3 \\
400 & 118 & -70.5 & 583 & 45.8 \\
500 & 107 & -78.6 & 709 & 41.8 \\
\hline
\end{tabular}
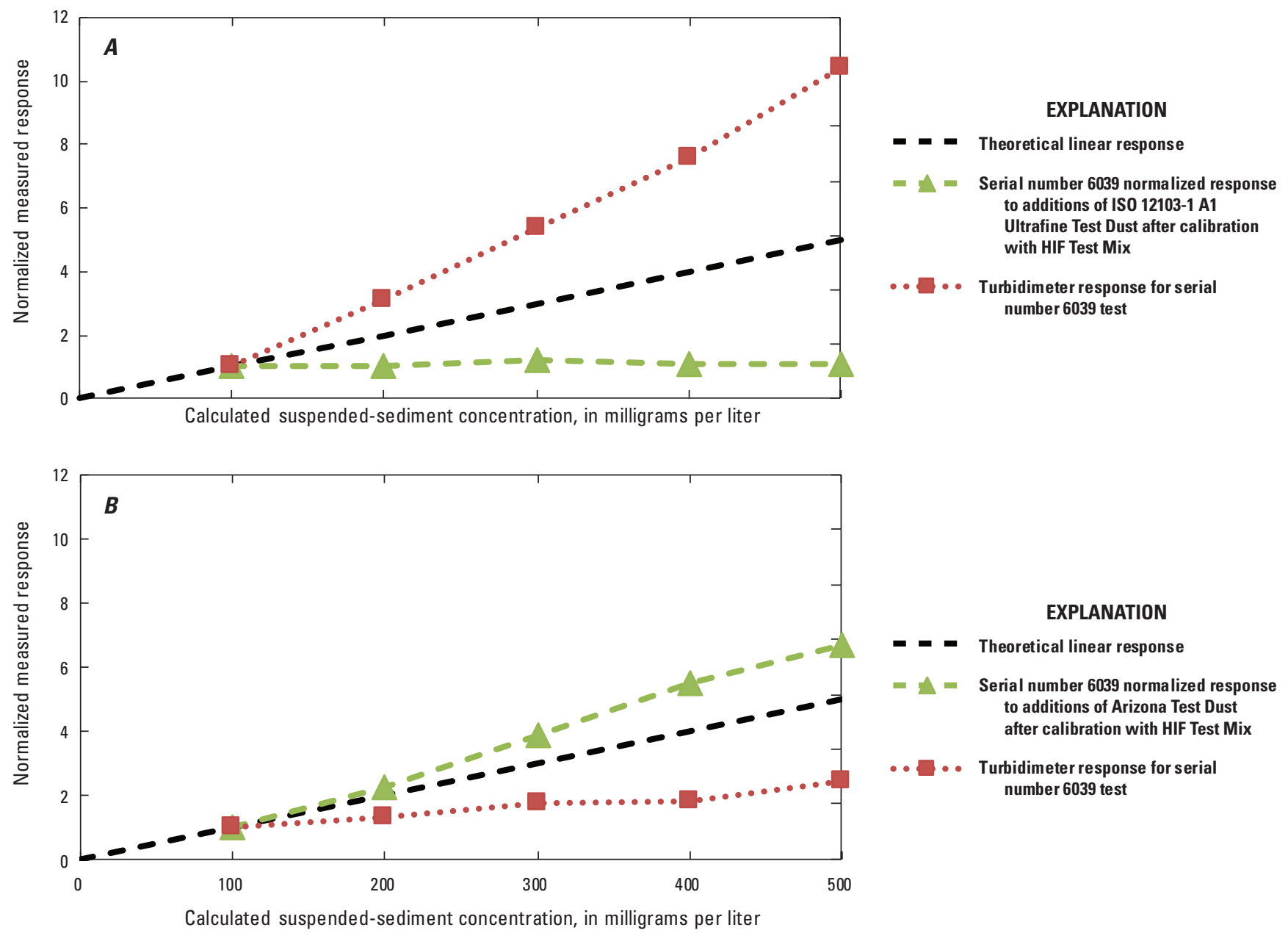

Figure 12. The theoretical linear and normalized responses of sensor 6039 and the resulting suspended-sediment concentrations to additions of $(A)$ ISO 12103-1, A1 Ultrafine Test Dust and $(B)$ Arizona Test Dust, after calibration with HIF test mix. Also shown as red squares are the normalized responses of the Hach $2100 \mathrm{~N}$ benchtop turbidimeter from the two tests. 


\section{Test Results: Extended Temperature Testing of Sensor 6039}

Test results of sensor 6039 showed a dramatic improvement over sensor 6010 in temperature compensation and performance in an extended temperature test. Measured SSC decreased slightly at higher temperatures (fig. 13), but this effect was caused by a reduction in water density due to increasing temperatures, thus causing sediment to fall out at the inefficient mixing speed. This effect was rectified when the mixer speed was increased to maintain a uniform solution. The maximum difference from the initial SSC value of $99.69 \mathrm{mg} / \mathrm{L}$ was 28.7 percent after the mixer speed was adjusted. The maximum difference from the temperature testing of sensor 6010 was 474 percent.

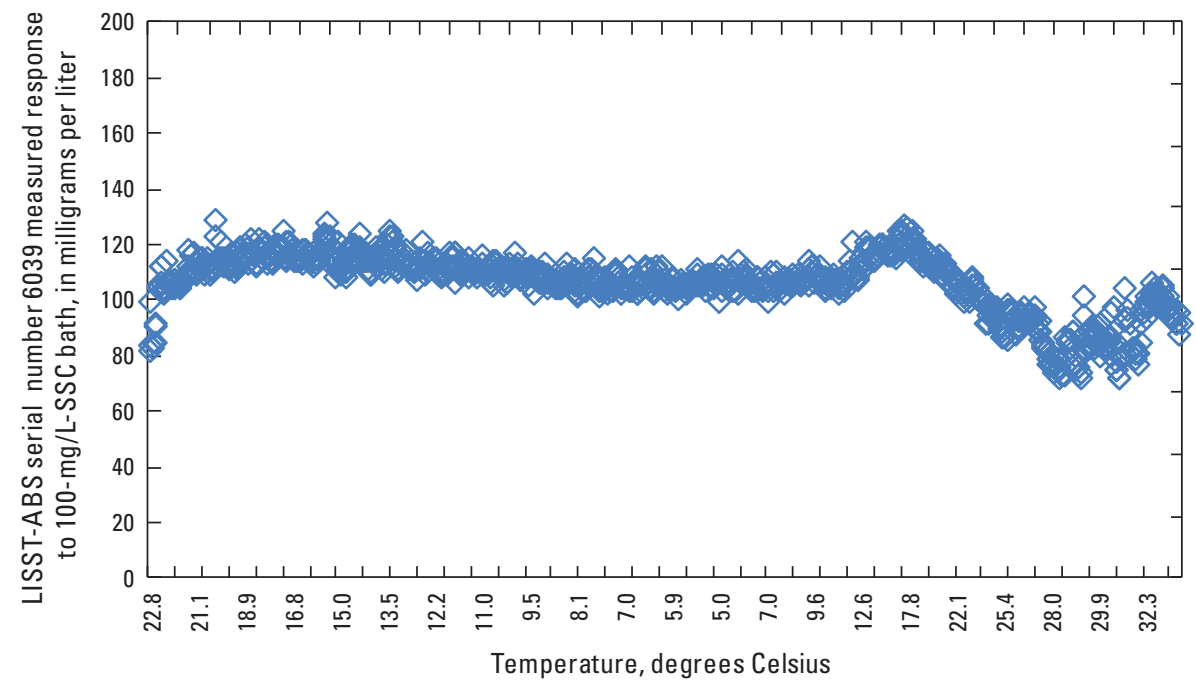

Figure 13. The effects of varying temperatures on measured suspended-sediment concentration of a 100-milligram-per-liter Arizona Test Dust solution during the temperature test of Sequoia Scientific LISST-ABS (sensor 6039).

\section{Test Procedures: Room-Temperature Testing of Sensor 6058}

Sensor 6058 was also tested at room temperature to evaluate the effect of varying particle-size distribution on accuracy. For the first test, the effect of Silica Dust on a finer sediment calibration (Ultrafine Test Dust) was evaluated for this sensor. The ABS was calibrated with a 100-mg/L SSC solution of Ultrafine Test Dust in water, and fractions of Silica Dust were added to create 200-, 300-, and 400-mg/L SSC solutions. Measured and sample SSCs were recorded along with temperature and turbidity for each SSC solution. Sensor 6058 was also calibrated with a 100-mg/L solution of $149 \mu \mathrm{m}$ Silica Dust and subjected to fractions of the Ultrafine Test Dust as the test sediment. Temperature, turbidity, sample SSC, and measured SSC were recorded for the 100-mg/L Silica Dust calibration solution and also after each addition of Ultrafine Test Dust to create 200-, 300-, and 400-mg/L SSC solutions. The ABS was not recalibrated for the changes in the solution particle-size distribution in either test, and temperature, turbidity, and measured SSC were recorded for each SSC solution.

\section{Test Results: Room-Temperature Testing of Sensor 6058}

The first room-temperature test in which the ABS was calibrated with Ultrafine Test Dust and tested with Silica Dust showed similar results to those from sensor 6039. Table 12 lists the data from the test, and figure 14 shows the shows the normalized response of sensor 6058 with an Ultrafine Test Dust calibration to increasing proportions of Silica Dust to the test bath. Like sensor 6039, the addition of the much coarser silica to the ultrafine sediment suspension had a significant effect on the measurement accuracy of sensor 6058, and the measured response was biased high when compared to the response of the benchtop turbidimeter. 
Table 12. Sequoia Scientific LISST-ABS (serial number 6058) SSC measurements showing the effect of MIL-STD-810E Silica Dust on the ISO 12103-1, A1 Ultrafine Test Dust calibration.

[g, gram; SSC, suspended-sediment concentration; mg/L, milligram per liter; FNU, formazin nephelometric units; n/a, not applicable]

\begin{tabular}{ccccccc}
\hline $\begin{array}{c}\text { Added fraction } \\
(\mathbf{g})\end{array}$ & Added sediment & $\begin{array}{c}\text { Calibration to added } \\
\text { sediment ratio }\end{array}$ & $\begin{array}{c}\text { Turbidity } \\
\text { (FNU) }\end{array}$ & $\begin{array}{c}\text { Sample SSC } \\
\text { ( } \mathbf{m g} / \mathbf{L})\end{array}$ & $\begin{array}{c}\text { Measured SSC } \\
\text { (mg/L) }\end{array}$ & $\begin{array}{c}\text { Percent } \\
\text { difference }\end{array}$ \\
\hline 0 & none & n/a & 0.51 & 0 & 8.1 & $\mathrm{n} / \mathrm{a}$ \\
2.49 & Ultrafine Test Dust & (calibration) & 64.4 & 100 & 104 & 4.0 \\
2.50 & Silica Dust & $1: 1$ & 91.7 & 200 & 438 & 119.0 \\
2.52 & Silica Dust & $1: 2$ & 124 & 300 & 1,076 & 258.7 \\
2.50 & Silica Dust & $1: 3$ & 150.1 & 400 & 1,386 & 246.5 \\
\hline
\end{tabular}

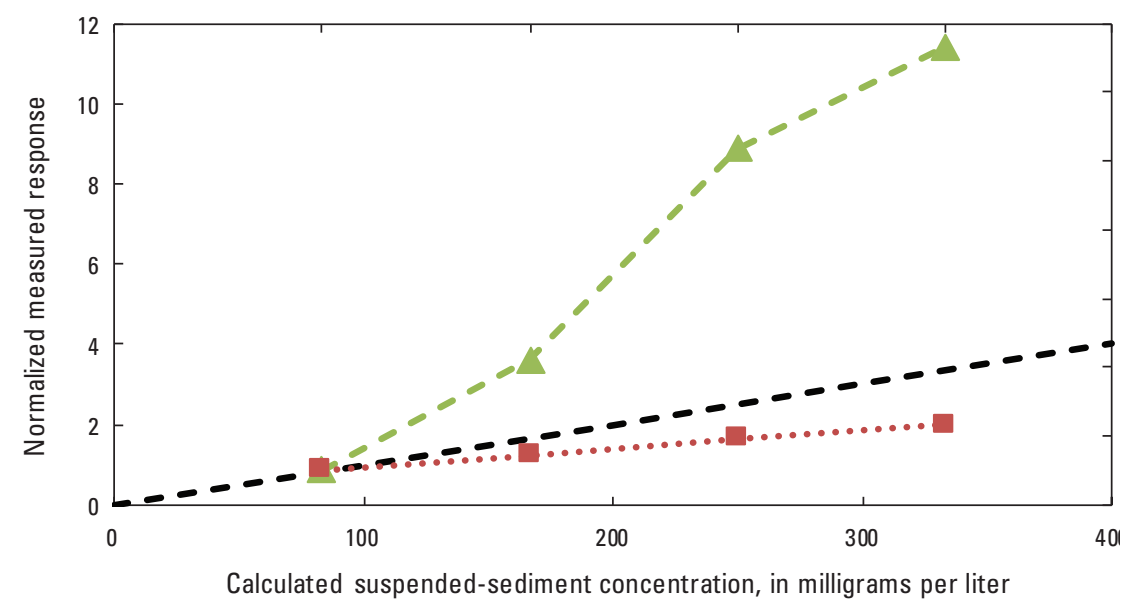

EXPLANATION

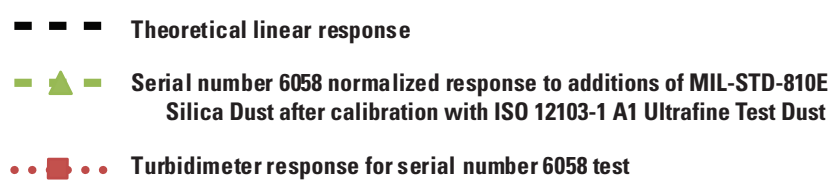

Figure 14. The theoretical linear and normalized response of sensor 6058, and the resulting suspended-sediment concentration to additions of MIL-STD-810E Silica Dust, after calibration with ISO 12103-1, A1 Ultrafine Test Dust. Also shown as red squares are the normalized responses of the Hach $2100 \mathrm{~N}$ benchtop turbidimeter in comparison.

Results of the second room-temperature test for sensor 6058 showed a suppression in response when the sensor was calibrated with the coarser Silica Dust and used to measure increasing fractions of the Ultrafine Test Dust. Table 13 lists the data collected from this test. Figure 15 shows the effect of the Ultrafine Test Dust on the measurement accuracy of ABS sensor 6058 with a Silica Dust calibration. Similar to sensor 6039 results, the additions of the smaller particle-size fractions of Ultrafine Test Dust (silt) were not effectively measured by the ABS. 
Table 13. Sequoia Scientific LISST-ABS (serial number 6058) SSC measurements showing the effect of ISO 12103-1, A1 Ultrafine Test Dust on the MIL-STD-810E Silica Dust calibration.

[g, gram; SSC, suspended-sediment concentration; mg/L, milligram per liter; FNU, formazin nephelometric units; n/a, not applicable]

\begin{tabular}{ccccccc}
\hline $\begin{array}{c}\text { Added fraction } \\
(\mathbf{g})\end{array}$ & Added sediment & $\begin{array}{c}\text { Calibration to added } \\
\text { sediment ratio }\end{array}$ & $\begin{array}{c}\text { Turbidity } \\
\text { (FNU) }\end{array}$ & $\begin{array}{c}\text { Sample SSC } \\
\text { (mg/L) }\end{array}$ & $\begin{array}{c}\text { Measured SSC } \\
\text { (mg/L) }\end{array}$ & $\begin{array}{c}\text { Percent } \\
\text { difference }\end{array}$ \\
\hline 0 & none & n/a & 1.4 & 0 & 4.4 & $\mathrm{n} / \mathrm{a}$ \\
2.50 & Silica Dust & (calibration) & 28.2 & 100 & 100 & 0.0 \\
2.50 & Ultrafine Test Dust & $1: 1$ & 95.1 & 200 & 119 & -40.5 \\
2.50 & Ultrafine Test Dust & $1: 2$ & 154 & 300 & 124 & -58.7 \\
2.51 & Ultrafine Test Dust & $1: 3$ & 197 & 400 & 121 & -69.8 \\
\hline
\end{tabular}

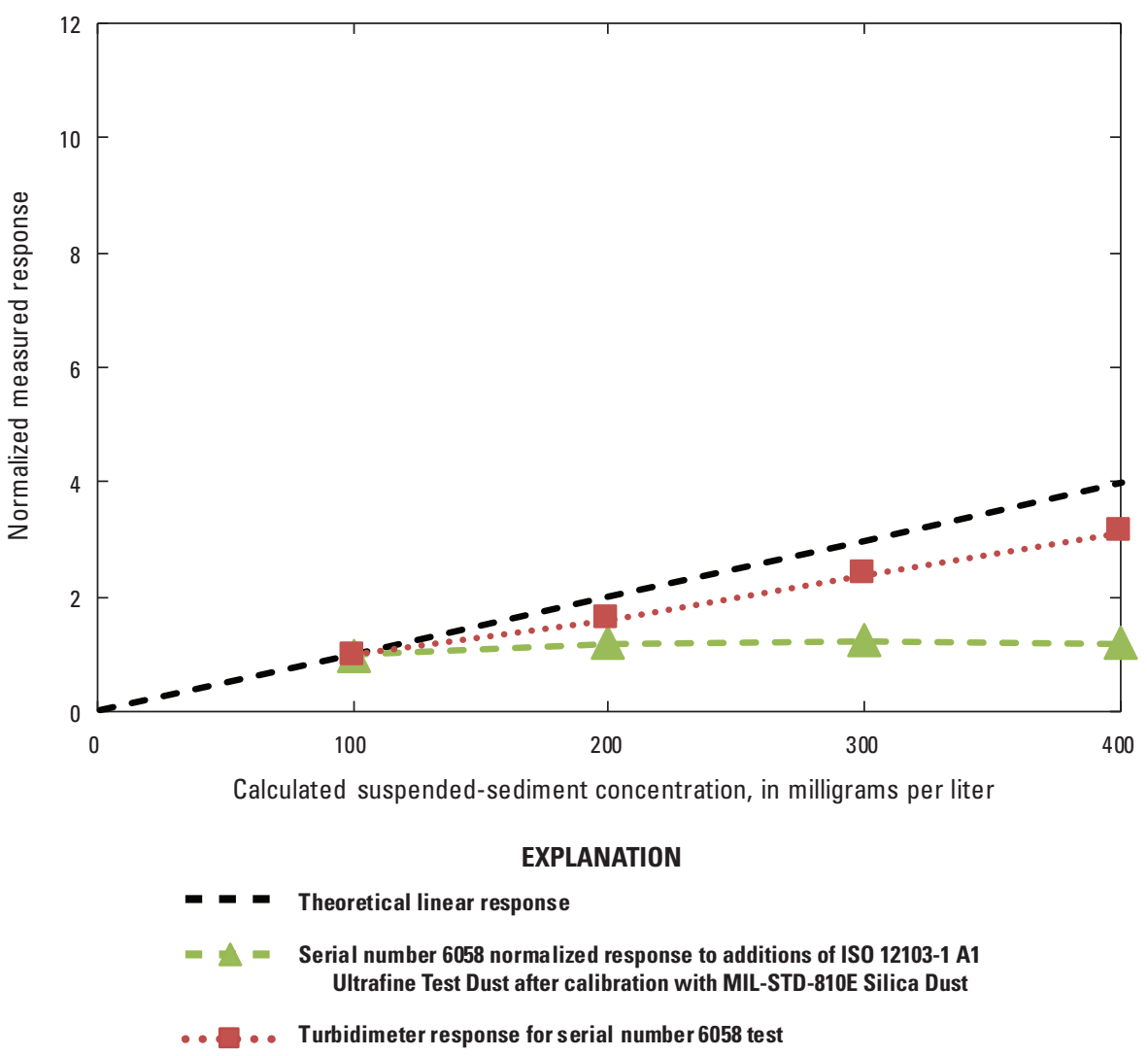

Figure 15. The theoretical linear and measured response of sensor 6058 , and the resulting suspended-sediment concentration in milligrams per liter, to additions of ISO 12103-1, A1 Ultrafine Test Dust, after calibration with MIL-STD-810E Silica Dust. Also shown as red squares are the normalized responses of the Hach $2100 \mathrm{~N}$ benchtop turbidimeter in comparison. 


\section{Discussion}

Reliable and accurate in situ monitoring of suspended-sediment concentration is complicated by the challenges of calibrating sensors to accurately work in temporally and spatially changing suspended-sediment concentrations. HIF's limited testing of the Sequoia Scientific LISST-ABS revealed an important flaw in the ability of sensor 6010 to compensate for the effect of temperature on the transducer. Overall testing revealed that an ABS calibrated with a coarser particle-size distribution underdetects the finer, smaller-sized particle suspended-sediments, and an ABS calibrated with fine sediment overdetects larger-sized particle suspended-sediment concentrations. Sensor 6010 had good linearity when calibrated properly with the sample sediment. When calibrated for Ultrafine Test Dust, measurement accuracy was negligibly affected by the addition of coarser particle-sized Silica Dust. Measurements using a calibration for Arizona Test Dust resulted in a low bias with the additions of Silica Dust.

Sensor 6039 showed improvement when tested for the effect of temperature on the measured response, but demonstrated a non-linear response when calibrated with Ultrafine Test Dust and subjected to Silica Dust additions. Also, additions of Ultrafine Test Dust were not registered when measured by sensor 6039 based upon a Silica Dust calibration. Additions of Ultrafine Test Dust were registered by the turbidimeter, and its measured response was much more linear than that of the ABS with a coefficient of determination $\left(\mathrm{R}^{2}\right)$ of 0.974 as compared to the $\mathrm{R}^{2}$ of 0.678 for the ABS.

The opportunity to test a third sensor, serial number 6058, allowed for the duplication of two tests. These tests in which the sensors were calibrated with an Ultrafine Test Dust and tested with Silica Dust showed a close correlation between the results from sensor 6058 and sensor 6039, and questioned the validity of the mixed calibration/test dust results from the initial sensor (6010; fig. 16). The data overlaps give credence to the test results and validate previous studies showing the limitations of turbidity sensors when measuring waters with coarser particle-size distribution (Merten and others, 2014).

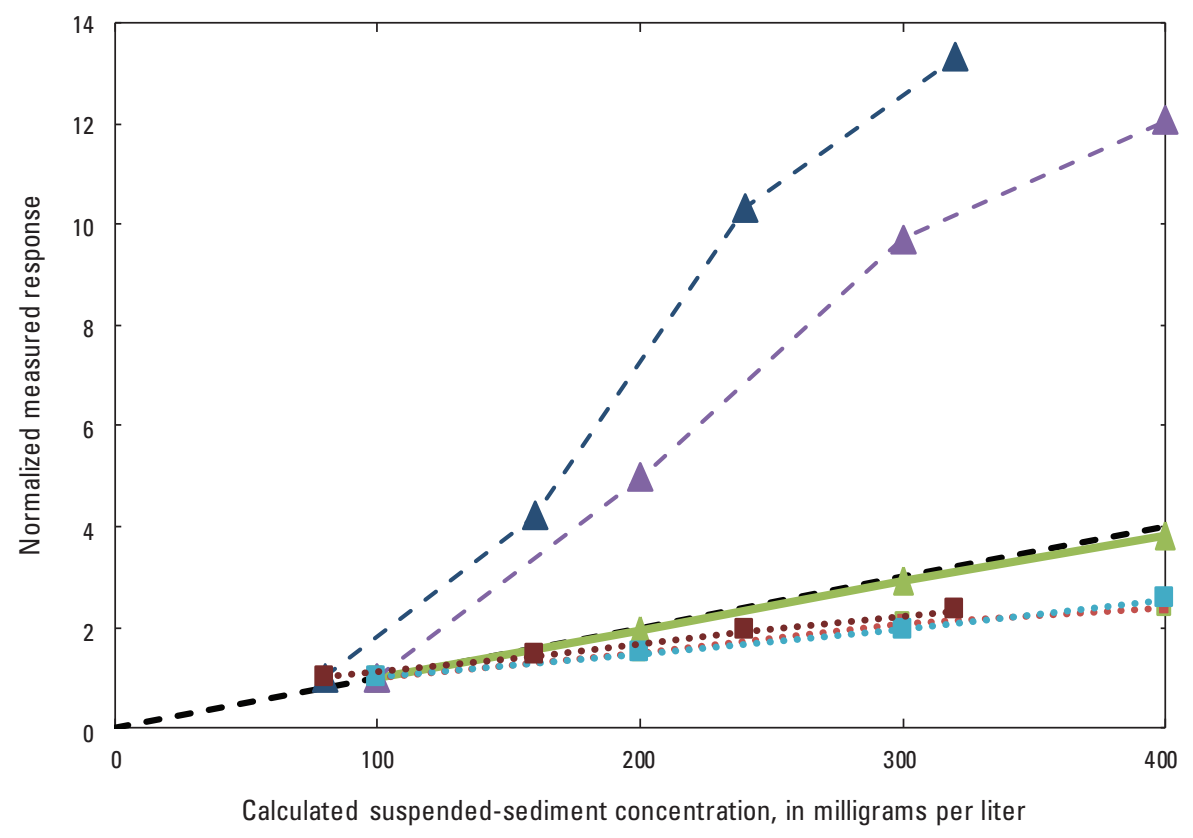

EXPLANATION

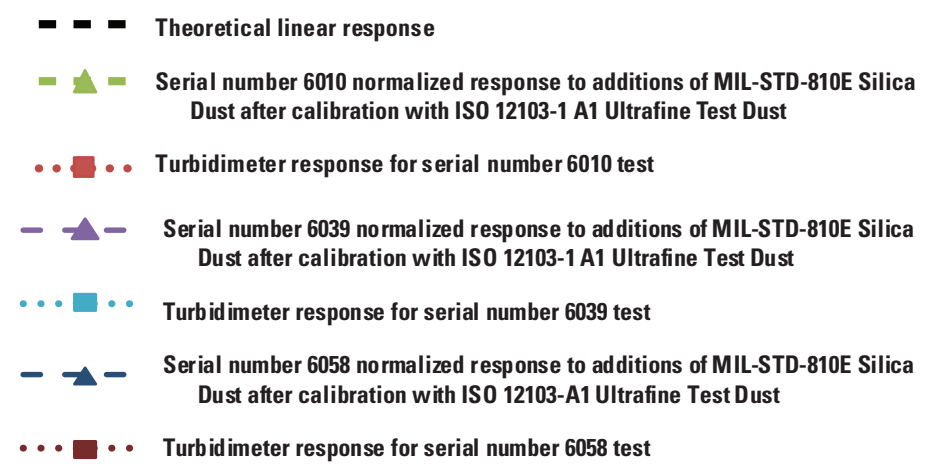

Figure 16. The theoretical linear and normalized response of sensors 6010,6039 , and 6058 and the resulting suspended-sediment concentration to additions of MIL-STD-810E Silica Dust, when calibrated with ISO 12103-1, A1 Ultrafine Test Dust. Also shown are the normalized responses of the Hach $2100 \mathrm{~N}$ benchtop turbidimeter from each test. 
The data from the tests from sensors 6039 and 6058 calibrated with Silica Dust and subjected to Ultrafine Test Dust are shown in figure 17. Test results show a similar trend in the data in which both sensors failed to register the addition of the finersized sediment. The increase in SSC was registered by the turbidimeter in both datasets.

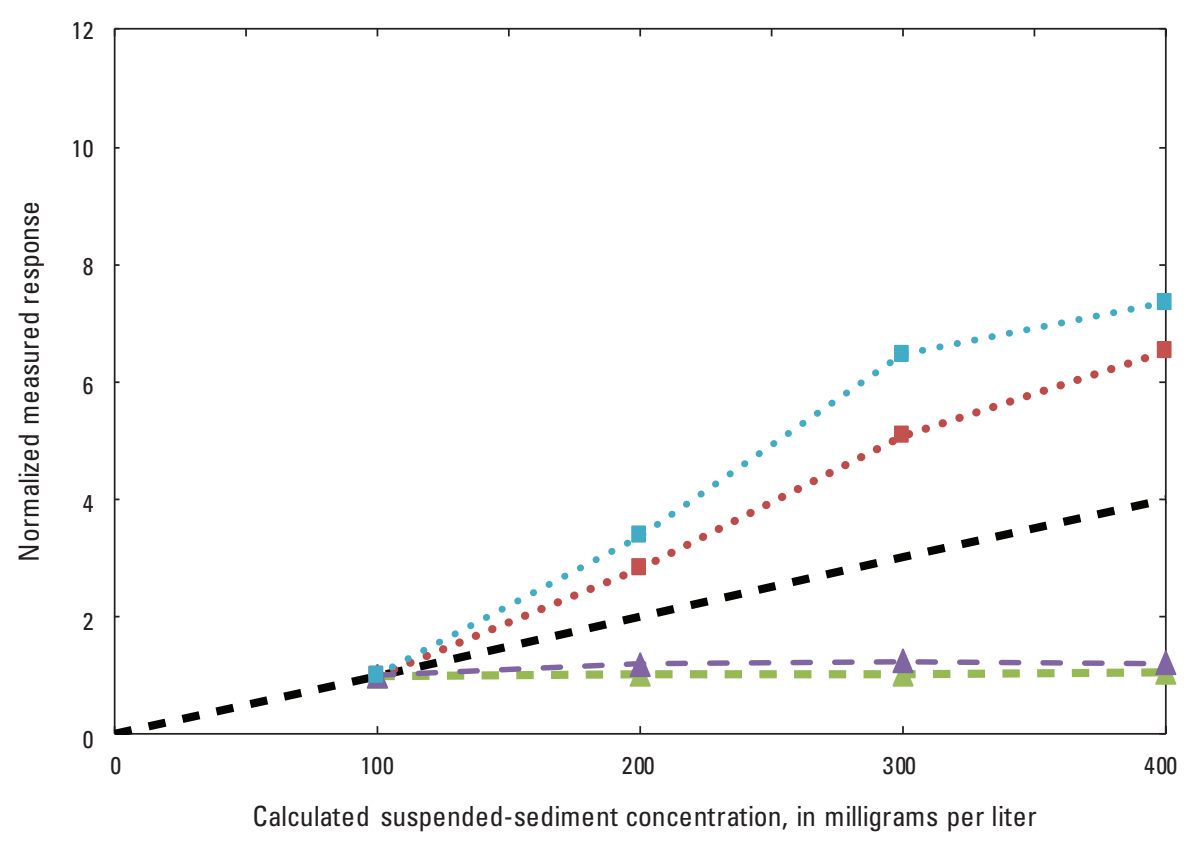

EXPLANATION

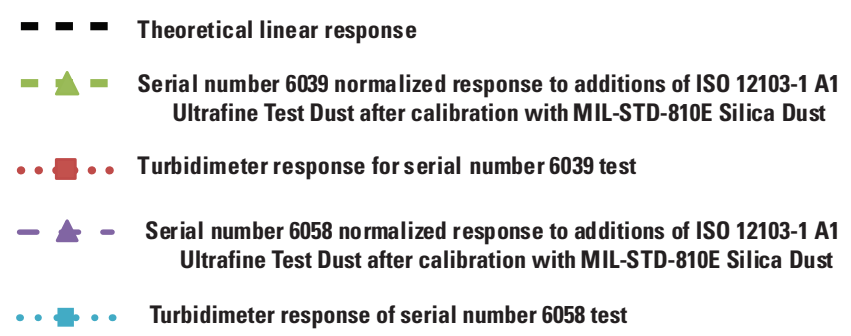

Figure 17. Plot showing the theoretical linear and normalized responses of sensors 6039 and 6058, and the resulting suspended-sediment concentrations, to additions of ISO 12103-1, A1 Ultrafine Test Dust, when calibrated with MIL-STD-810E Silica Dust. Also shown are the normalized responses of the Hach $2100 \mathrm{~N}$ benchtop turbidimeter from each test.

\section{Summary}

Sequoia Scientific's LISST-ABS is an acoustic backscatter sensor designed to measure suspended-sediment concentration at a point source. The ABS was evaluated at the HIF for accuracy and temperature operating range. Test results showed that the sensor is able to accurately measure SSC when calibrated properly to the sample sediment. Test results of three different sensors show that the sensor accuracy is affected significantly when the calibration sediment does not reflect changes in particle-size distribution of the measured SSC. When calibrated with Ultrafine Test Dust (silt) and with Arizona Test Dust (30-80- $\mu \mathrm{m}$ range), the data from sensor 6039 and from sensor 6058 were biased high when fractions of Silica Dust were added to the calibration solution. Data from sensor 6010 showed little effect of Silica Dust on the less than $22-\mu \mathrm{m}$ particle-sized calibration (Ultrafine), but subsequent testing revealed problems with this sensor, thus causing doubt about the validity of the test results. Overall testing revealed a subdued response when the ABS was calibrated with a coarser particle-size distribution and exposed to finer, smaller-sized particles, and an exaggerated effect when calibrated with fine sediment and exposed to a larger-sized particle distribution. Turbidimeter results showed an opposite reaction to the ABS and demonstrated a subdued response to increased SSC by the addition of coarser sediment such as sand. These test results are not unexpected, but indicate sensor data at a dynamic site 
could be biased either high or low depending on changing sediment size distribution. Corroborating turbidity data from each test was repeatable, and not only verified the changes in SSC that occurred during testing, but also validated the quality of the evaluation overall.

HIF's limited testing of the Sequoia Scientific LISST-ABS revealed an important flaw in the ability of sensor 6010 to compensate for the effect of temperature on the transducer. The problems found with sensor 6010 resulted in a new sensor design and updated firmware by the vendor. The extended temperature test results for sensor 6039 showed a significant improvement in performance with a reduction in the maximum difference between sample and measured SSC from 474 percent to 28.7 percent.

\section{References Cited}

Anderson, C.W., 2005, Turbidity: U.S. Geological Survey Techniques of Water-Resources Investigations, book 9, chap. A6, sec. 6.7, July 2006, accessed March 2, 2015, at http://pubs.water.usgs.gov/twri9A6/.

Czuba, J.A., Straub, T.D., Curran, C.A., Landers, M.N., and Domanski, M.M., 2015, Comparison of fluvial suspendedsediment concentrations and particle-size distributions measured with in-stream laser diffraction and in physical samples: Water Resources Research, v. 51, no. 1, p. 320-340, accessed May 31, 2017, at http://onlinelibrary.wiley.com/ doi/10.1002/2014WR015697/full.

Hach Company, 2014, DOC022.97.80203, 2100N, Basic user manual, edition 5.

International Organization for Standardization (ISO), 1997, International Standard ISO 12103-1, Road vehicles—-Test dust for filter evaluation (1st ed.).

Landers, M.N., Straub, T.D., Wood, M.S., and Domanski, M.M., 2016, Sediment acoustic index method for computing continuous suspended-sediment concentrations: U.S. Geological Survey Techniques and Methods, book 3, chap. C5, 63 p., accessed May 31, 2017, at http://dx.doi.org/10.3133/tm3C5.

Merten, G.H., Capel, P.D., and Minella, J.P.G., 2014, Effects of suspended-sediment concentration and grain size on three optical turbidity sensors: Journal of Soils and Sediments, v. 14, no. 7, p. 1235-1241, accessed May 31, 2017, at https://doi. org/10.1007/s11368-013-0813-0.

Powder Technology Inc., 2015, Material particle size distribution PTI ID\# 12778A, 12765A, and 12544C.

Sequoia Scientific, 2016a, LISST-ABS submersible acoustic backscatter sensor product sheet, accessed June 1, 2016, at http:// www.sequoiasci.com/product/lisst-abs/.

Sequoia Scientific, 2016b, How the LISST-ABS works, accessed May 1, 2016, at http:/www.sequoiasci.com/article/ how-the-lisst-abs-works/.

Sequoia Scientific, 2016c, LISST-ABS acoustic backscatter sensor user's manual, version 1.2, 35 p.

U.S. Department of Defense, 1989, Military standard, environmental test methods and engineering guidelines: United States Department of Defense MIL-STD-810E [variously paged]. 
For more information about this publication, contact

Chief, Hydrologic Instrumentation Facility

U.S. Geological Survey

Building 2101

Stennis Space Center, MS 39529

For additional information visit

https://water.usgs.gov/hif/

Publishing support provided by

Lafayette Publishing Service Center 



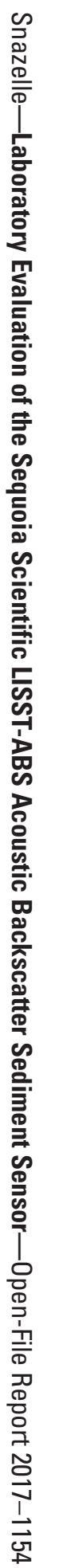

